OPEN ACCESS

Edited by:

Nashat Abumaria,

Fudan University, China

Reviewed by:

Sandra Blaess,

University of Bonn, Germany

Noël Ghanem,

American University of Beirut,

Lebanon

${ }^{*}$ Correspondence:

Jialing Liu

jialing.liu@ucsf.edu

Received: 27 July 2016 Accepted: 26 September 2016

Published: 17 October 2016

Citation:

Kobeissy FH, Hansen K, Neumann M,

Fu S, Jin K and Liu J (2016)

Deciphering the Role of Emx1 in

Neurogenesis: A Neuroproteomics

Approach. Front. Mol. Neurosci. 9:98.

doi: 10.3389/fnmol.2016.00098

\section{Deciphering the Role of Emx1 in Neurogenesis: A Neuroproteomics Approach}

\author{
Firas H. Kobeissy ${ }^{1}$, Katharina Hansen ${ }^{2,3}$, Melanie Neumann ${ }^{2,3}$, Shuping $\mathrm{Fu}^{2,3,4}$, Kulin Jin $^{5}$ \\ and Jialing $\mathrm{Liu}^{2,3 *}$
}

${ }^{1}$ Department of Psychiatry, Center for Neuroproteomics and Biomarkers Research, University of Florida, Gainesville, FL, USA, ${ }^{2}$ Department of Neurological Surgery, University of California, San Francisco, San Francisco, CA, USA, ${ }^{3}$ San Francisco VA Medical Center, San Francisco, CA, USA, ${ }^{4}$ Key Laboratory of Acupuncture and Medicine Research of Minister of Education, Nanjing University of Chinese Medicine, Nanjing, China, ${ }^{5}$ Pharmacology \& Neuroscience, University of North Texas Health Science Center, Fort Worth, TX, USA

Emx1 has long been implicated in embryonic brain development. Previously we found that mice null of Emx1 gene had smaller dentate gyri and reduced neurogenesis, although the molecular mechanisms underlying this defect was not well understood. To decipher the role of Emx1 gene in neural regeneration and the timing of its involvement, we determine the frequency of neural stem cells (NSCs) in embryonic and adult forebrains of Emx1 wild type (WT) and knock out (KO) mice in the neurosphere assay. Emx1 gene deletion reduced the frequency and self-renewal capacity of NSCs of the embryonic brain but did not affect neuronal or glial differentiation. Emx1 KO NSCs also exhibited a reduced migratory capacity in response to serum or vascular endothelial growth factor (VEGF) in the Boyden chamber migration assay compared to their WT counterparts. A thorough comparison between NSC lysates from Emx1 WT and KO mice utilizing 2D-PAGE coupled with tandem mass spectrometry revealed 38 proteins differentially expressed between genotypes, including the F-actin depolymerization factor Cofilin. A global systems biology and cluster analysis identified several potential mechanisms and cellular pathways implicated in altered neurogenesis, all involving Cofilin1. Protein interaction network maps with functional enrichment analysis further indicated that the differentially expressed proteins participated in neural-specific functions including brain development, axonal guidance, synaptic transmission, neurogenesis, and hippocampal morphology, with VEGF as the upstream regulator intertwined with Cofilin1 and Emx1. Functional validation analysis indicated that apart from the overall reduced level of phosphorylated Cofilin1 (p-Cofilin1) in the Emx1 KO NSCs compared to WT NSCs as demonstrated in the western blot analysis, VEGF was able to induce more Cofilin1 phosphorylation and FLK expression only in the latter. Our results suggest that a defect in Cofilin1 phosphorylation induced by VEGF or other growth factors might contribute to the reduced neurogenesis in the Emx1 null mice during brain development.

Keywords: cofilin, VEGF, neural stem cell, 2D-PAGE/MS-MS, Boyden chamber assay 


\section{INTRODUCTION}

Mammalian homeobox gene transcription factors including the Emx, Hox, Pax, and Dlx, have been implicated in the development of the forebrain (Boncinelli et al., 1995; Panganiban and Rubenstein, 2002; Gavalas et al., 2003; Muzio and Mallamaci, 2003; de Melo et al., 2005). Among which, the Emx family plays a crucial role in neurogenesis including neuronal migration, differentiation, and synaptic connectivity (Simeone et al., 1993). As the homolog of the Drosophila melanogaster empty spiracles ems gene, the Emx genes are well conserved in mammals and insects, sharing $\sim 82 \%$ homology in amino acid identity with the ems homeodomains (Cecchi and Boncinelli, 2000).

Two of the Emx1 isoforms, $E m x 1$ and $E m \times 2$, share a number of functional and structural characteristics with overlapping patterns of spatio-temporal expression (Simeone et al., 1992; Gulisano et al., 1996; Chan et al., 2001). Whereas, Emx2 is expressed in the dorsal and ventral telencephalon and hypothalamus, $E m x 1$ is restricted to the dorsal telencephalon (Simeone et al., 1992). Single Emx1 mutants showed a lack of corpus callosum with minimal structural or histological brain anomalies in contrast to the profound and severe developmental defects observed in Emx2 mutants, such as disorganized olfactory bulb and reduced size of the cerebral cortex and hippocampus (Pellegrini et al., 1996; Qiu et al., 1996; Bishop et al., 2003). With respect to neurogenesis, we have demonstrated that Emx1, similar to $E m x 2$, contributed to the genesis of the dentate gyrus (DG). Apart from the impairment in skill reaching learning, as well as blunted anxiety and depression (Cao and Li, 2002), the adult Emx1 mutants exhibited smaller DG, coinciding with a decreased number of immature neurons and proliferating progenitor cells in the DG (Hong et al., 2007). However, the mechanism by which Emx1 contributes to neurogenesis and the critical developmental stage involving Emx1 is not well understood.

Neurogenesis encompasses several processes including the proliferation and differentiation of neural stem cells (NSCs), as well as the migration and survival of newborn neurons (Frisén, 2016; Liu and Song, 2016). Established evidence suggests that neuroblasts migrate in close association with blood vessels following the division of NSCs (Thored et al., 2007; Zhang et al., 2014). A number of vascular factors including VEGF contribute to the formation and maintenance of the neurovascular niche of neurogenesis ( $\mathrm{Li}$ Q. et al., 2006; Madri, 2009; Ward and Cunningham, 2015). The current study sought to decipher the role of the Emx1 gene in reduced neural regeneration and determine the putative mechanisms implicated by employing neuroproteomics-systems biology platforms and biochemical approaches. Our results indicate that $E m x 1$ gene deletion not only resulted in reduced embryonic neurosphere formation with diminished self-renewal capacity, but also negatively impacted the chemotaxic response of NSCs to VEGF or serum. Proteomics analysis suggests that the deficiency in Cofilin1 phosphorylation may underlie the defective signaling of NSCs in response to VEGF or other growth factors, potentially leading to abnormal forebrain development.

\section{MATERIALS AND METHODS}

\section{Animals, Housing, and Ethical Considerations}

This study was conducted in accordance with the animal care guidelines issued by the National Institutes of Health and by the San Francisco Veterans Affairs Medical Center Animal Care and Use Committee. Adult mice heterozygous for Emx1 gene derived from cryopreserved embryos at Jackson Laboratory were bred to generate heterozygous and homozygous offspring that were maintained in house in the institutional standard cages (4 mice per cage) on a 12-h light/12-h dark cycle, with ad libitum access to water and food before and during experimental procedures. All in-vitro and in-vivo procedures were conducted by examiners blinded to experimental conditions (for the detailed methodology of Western blot analysis and antibodies used, please refer to Data Sheet 1 in the Supplementary Material).

\section{Neural Stem Cell Culture and Neurosphere Assay}

Forebrains were dissected from Emxl WT or KO embryos at embryonic day 14 (E14) harvested from time-pregnant mice. Neurosphere assay for the adult mice (2.5 months of age) were conducted from the dissected subventricular zone (SVZ) or the hippocampus. After enzymatic digestion with Papain $(10 \mathrm{U} / \mathrm{ml})$ and DNase $(0.5 \mathrm{mg} / \mathrm{ml})$ (Sigma Aldrich, St. Louis, MO, USA) solution at $37^{\circ} \mathrm{C}$ for $20 \mathrm{~min}$, brain tissue was mechanically triturated with a fire-polished Pasteur pipette into single cell suspension and resuspended in DMEM-F12 (1:1) medium in the presence of hEGF $(20 \mathrm{ng} / \mathrm{ml})$ or hEGF $(20 \mathrm{ng} / \mathrm{ml})+$ FGF $(10 \mathrm{ng} / \mathrm{ml})$ (Invitrogen, Eugene, Oregon, USA) and heparin $(2 \mu \mathrm{g} / \mathrm{ml})$ (StemCell Technologies, Inc., Vancouver, BC, Canada). Neural colony forming cell (NCFC) assay kit (StemCell Technologies, Inc., Vancouver, BC, Canada) was used for neurosphere assay. Cells were suspended in complete NeuroCult NCFC medium, and mixed with collagen solution, 7500 cells were dispensed into $35 \mathrm{~mm}$ culture dishes and cultured for 21 days. hEGF and FGF-2 (20 ng/ml each) was added into the semi-solid culture every 7 days. The diameters of spheres were measured using a $2 \mathrm{~mm}$-grid dish on a Zeiss invert microscope. Remaining cells were suspended in proliferation medium composed of DMEM/F-12 (1:1) containing B27 supplement and $20 \mathrm{ng} / \mathrm{ml} \mathrm{hEGF}$, and were cultured in a T75 tissue culture flask to form primary floating neurospheres. Floating neurospheres were passaged every 7 days.

\section{Neural Stem Cells Self-Renewal Capacity}

Primary neurospheres were mechanically dissociated into single cells suspension and $\sim 400$ viable cells were plated into each well of a 6-well cell culture plate containing proliferation medium. The number of secondary neurospheres generated in each well was counted 10 days after plating and averaged $(n=3-4$ replicates/neurosphere samples/genotype).

\section{Neural Stem Cell Differentiation Assay and Immunocytochemistry}

Neurospheres were harvested after 2 nd passage by centrifugation at $500 \mathrm{rpm}$ for $5 \mathrm{~min}$ and resuspended in growth factor-free 
DMEM/F-12 (1:1) medium. Cells in neurospheres were mechanically dissociated by trituration and filtered through $0.45 \mu \mathrm{m}$ cell strainer. Viable single cells $\left(10^{5}\right.$ cells/well $)$ were plated on poly-D-lysine/laminin coated 6-well culture plate in DMEM-F12 (1:1) plus NeuroCult NSFC differentiation supplements for 10 days. The differentiated cells were fixed with $4 \%$ paraformaldehyde in $0.1 \mathrm{M}$ PBS for $15 \mathrm{~min}$, and then washed with PBS twice. Differentiated cells were immunostained with following reagents: mouse anti-GFAP; mouse anti-Tuj1; rat anti-nestin; Cy3 goat anti-mouse; biotinylated sheep anti-rat; Cy3 streptavidine. Cells were count stained with DNA dye Hoechst. Stained cells were photographed with a Zeiss invert fluorescence microscope. Differentiation ratio was calculated as immuno-positive cells divided by total cells stained with Hoechst.

\section{Boyden Chamber Chemotaxis Assay}

The migration of the NSCs in response to fetal calf serum (FCS) or recombinant human $\mathrm{VEGF}_{165}$ (R\&D Systems, Minneapolis, USA) was assessed using a modified Boyden chamber assay as previously described (Lamszus et al., 1998; Schmidt et al., 2009). Briefly, quadruplicates of media containing $10 \%$ FCS or VEGF were added to the lower wells of a 96-well modified Boyden chamber (Neuro Probe, Gaithersburg, MD, USA), and wells were covered with an $8-\mu \mathrm{m}$ pore size Nucleopore filter that had previously been coated with $10 \mu \mathrm{g} / \mathrm{ml}$ laminin (Invitrogen, Eugene, Oregon, USA). NSCs from dissociated neurospheres passages 3-4 were then suspended at $2.5 \times 10^{4}$ cells in $50 \mu \mathrm{l}$ of either serum-free DMEM/F12 medium containing $0.1 \%$ bovine serum albumin (BSA) or in growth medium containing EGF alone or EGF+FGF and seeded into the upper wells. After incubation for $15 \mathrm{~h}$ at $37^{\circ} \mathrm{C}$, non-migrated cells were scraped off the upper side of the filter and filters were stained with Diff-Quik (VWR, Brisbane, CA, USA). Nuclei of migrated cells were counted in an average of 180 high power fields (field size $20 \times 20$ to $100 \times 100 \mu \mathrm{m}$ ) using a $40 \mathrm{x}$ objective by using the Stereo Investigator software (Stereo Investigator, MicroBrightField, VA). Values were assessed in quadruplicate from at least three independent experiments and expressed as mean \pm standard deviation in percentage of the control migration $(=100 \%)$. The control migration rate for each assay was assessed in response to either serum-free medium containing $0.1 \%$ BSA or growth medium containing EGF or EGF+FGF.

\section{Two-Dimensional Polyacrylamide Gel Electrophoresis (2D-PAGE) Sample Preparation}

Forty milliliters of NSCs (passage 2), seeded with a density of 100,000 cells $/ \mathrm{ml}$, were harvested after 5 days of growing in defined media by centrifugation at $400 \times \mathrm{g}$. Cell pellets were lysed in $1 \mathrm{ml}$ of lysis-buffer containing $9 \mathrm{M}$ urea (Sigma), 4\% (w/v) CHAPS (Calbiochem, San Diego, CA), $0.5 \%(\mathrm{v} / \mathrm{v})$ pharmalytes $\mathrm{pH}$ 3-10 (Amersham Bioscience), $1 \mathrm{mM}$ EDTA (American Bioanalytical, Natick, MA), Complete protease inhibitor tablets were from Roche (Indianapolis, IN). Homogenates were triturated using a syringe with 20G-needle and incubated for $1 \mathrm{~h}$ at RT. After samples were centrifuged at $4000 \mathrm{rpm}$ for $10 \mathrm{~min}$, supernatants were transferred into an empty $1.5 \mathrm{ml}$ tube, while pellets were discarded. To determine protein concentrations the 2-D-Quant-protein concentration kit (Amersham Bioscience) was used following the instructor's guideline. The first dimension was performed using an Ettan IPGphor II isoelectric focusing unit (Amersham Bioscience). Five-hundred micrograms of protein sample were mixed with $0.2 \%(\mathrm{v} / \mathrm{v})$ ampholytes (Amersham Bioscience) and $170 \mu \mathrm{l}$ of $2 \times$ rehydration-buffer containing $9 \mathrm{M}$ urea, $2 \%(\mathrm{w} / \mathrm{v})$ CHAPS, $0.002 \%$ (w/v) bromphenol blue, $18 \mathrm{~mm}$ of dithiothreitol (DTT (ThermoFisher), and 0.5\% IPG-buffer 3-10 (Amersham Bioscience). To reach the final volume of $340 \mu$ l, lysis-buffer (see above) was added. Each sample was pipetted into a slot of the dehydration tray in which an $18 \mathrm{~cm}$-Immobilene ${ }^{\mathrm{TM}}$ Dry Strip pH 3-10 (Amersham Bioscience) was placed upside down. In order to inhibit drying-out of the solution overnight each slot was covered with mineral oil (Amersham Bioscience). The strips passively rehydrated at constant $25^{\circ} \mathrm{C}$ for $18 \mathrm{~h}$. Afterwards the strips were transferred to the focusing tray where the proteins were separated according to their isoelectric points using the following protocol: $1 \mathrm{~h}$ at $150 \mathrm{~V}, 3 \mathrm{~h}$ at $300 \mathrm{~V}, 6 \mathrm{~h}$ at $1000 \mathrm{~V}$ using the linear ramp, $3 \mathrm{~h}$ at $6000 \mathrm{~V}$ using the linear ramp, and $3 \mathrm{~h}$ at $6000 \mathrm{~V}$. To inhibit diffusion of the proteins after focusing the machine held $50 \mathrm{~V}$ until manually stopped. After the focusing process strips were equilibrated two times for $10 \mathrm{~min}$ in a buffer containing $50 \mathrm{mM}$ of Tris- $\mathrm{HCl}(\mathrm{pH} 8.8), 6 \mathrm{M}$ Urea, 30\% (v/v) glycerol, 2\% (w/v) SDS, $0.002 \%(w / v)$ bromphenol blue and either $65 \mathrm{mM}$ DTT. Equilibrated strips were put on top of a $12 \%$ polyacrylamide gel, made by using standard laboratory procedures, and covered with $0.5 \%(\mathrm{w} / \mathrm{v})$ melted agarose also containing $0.002 \%(\mathrm{w} / \mathrm{v})$ bromphenol blue. Ten microliters of a molecular weight standard (BioRad, Hercules, CA) was dropped on a piece of blotting paper and was put next to the strip into the agarose solution before polymerization. Gels were run over night at $10 \mu \mathrm{A}$ per gel at $4^{\circ} \mathrm{C}$ using an Ettan DALTsix electrophoreses unit (Amersham Bioscience, Piscataway, NJ; for the detailed methodology of Gel staining with silver or Coomassie Blue, please refer to Data Sheet 1 in the Supplementary Material).

\section{High Performance Liquid Chromatography (HPLC) Tandem Mass Spectrometry (MS/MS)}

Peptide extracts were separated on-line by nanoLC utilizing a 2D LC NanoLC System (Eksigent/AB Sciex). Liquid chromatographic separations were performed using a PepMap (Dionex/LC Packings) trap column and a reversed phase nano-column $(75 \mu \mathrm{m}$ in diameter $\times 150 \mathrm{~mm}$ in height packed in-house with Jupiter Proteo C12 endcapped resin, $90 \AA$ pore size, $4 \mu \mathrm{m}$ particle size). An aliquot of peptide extract $(3-4 \mu \mathrm{L})$ was loaded onto the trap column with loading solvent $(0.1 \%$ formic acid) at a flow rate of $20 \mu \mathrm{L} / \mathrm{min}$. The trap column was washed with the loading solvent for 3 min prior to switching it in line with the reversed phase nano-column. The nano-column and elution buffers were maintained at ambient temperature and mobile phase flow rate was $250 \mathrm{~nL} / \mathrm{min}$. The nano-column was 
equilibrated with $2 \%$ Solvent B in Solvent A for 20 min prior to sample injection (Solvent A: $2 \%$ acetonitrile/0.1\% formic acid; Solvent B: $80 \%$ acetonitrile $/ 0.1 \%$ formic acid). Peptide separation was accomplished using a binary gradient which consisted of a $5 \mathrm{~min}$ isocratic wash at $2 \% \mathrm{~B}$ followed by a linear gradient of $2-50 \%$ B over $45 \mathrm{~min}$, and concluded with a column cleanup step of $95 \% \mathrm{~B}$ for $7 \mathrm{~min}$. The nano-column was interfaced directly to a nanoelectrospray ion source (Protana) mounted on a QSTAR Elite quadrupole/quadrupole/time-of-flight (QqTOF) mass spectrometer (AB Sciex). Protein identification was accomplished by isolating sequentially eluting peptide populations with a single mass-to-charge ratio $(\mathrm{m} / \mathrm{z})$, within the mass spectrometer, fragmenting this population, and measuring the masses of the peptide fragment ions. Peak lists were generated with the Mascot Daemon (Matrix Sciences) and the Mascot v2.2 search engine (Matrix Science) was used to search the experimentally determined peptide fragment ion masses against a theoretical fragment ion mass database generated by in silico digestion and fragmentation of all proteins in the UniProtKB/Swiss-Prot Protein Knowledgebase (downloaded 03-09-2011; 525,997 protein sequences; 185,874,894 residues), taxonomy: rodentia (25,596 protein sequences). The following search parameters were utilized: precursor ion mass tolerance \pm $150 \mathrm{ppm}$; fragment ion mass tolerance $0.15 \mathrm{Da}$; tryptic digestion; 2 missed cleavages; $p<0.05$; ion score or expect cut-off 0.05; fixed modification: Cys-carbamidomethyl; variable modifications: deamidation (Asn and Gln), Met-sulfoxide, and Pyro-glu (N-term Gln; for the detailed methodology of In-gel digestion procedure, please refer to Data Sheet 1 in the Supplementary Material).

\section{Subnetwork Enrichment Pathway Analyses and Statistical Testing}

The Elsevier's Pathway Studio v. 10.0 (Ariadne Genomics/Elsevier) was used to deduce relationships among differentially expressed proteomics protein candidates using the Ariadne ResNet database (Bonnet et al., 2009; Yuryev et al., 2009). "Subnetwork Enrichment Analysis" (SNEA) algorithm was selected to extract statistically significant altered biological and functional pathways pertaining to each identified set of protein hits SNEA utilizes Fisher's statistical test used to determine if there are nonrandom associations between two categorical variables organized by specific relationship. SNEA starts by creating a central "seed" from all relevant entities in the database, and retrieving associated entities based on their relationship with the seed (that is, binding partners, expression targets, protein modification targets, regulation). The algorithm compares the sub-network distribution to the background distribution using one-sided Mann-Whitney U-Test, and calculates a $p$-value indicating the statistical significance of difference between two distributions. In our analysis, "GenBank ID symbols" of the 38 altered proteins from 2D-PAGE-MS/MS spectrometry data were imported to the software to form an experimental data set. For the reconstruction of networks of pathways, biological processes, and Molecular function were evaluated for each single protein hit and its associated targets (networks and pathways; Daraselia et al., 2012; Pyatnitskiy et al.,
2014). Integrated Venn diagram analysis was performed using "the InteractiVenn": a web-based tool for the analysis of comlex data sets. Green rectangles, violet rectangles, and blue hexagons reflect biological processes, disease processes, and functional classes, respectively. The different colors of proteins reflect their degree of expression.

\section{Gene Ontology: Molecular Function, Biological Process, and Cellular Localization of EMX1 Differential Proteome}

Differentially expressed proteins were GO-classified based on the PANTHER (Protein ANalysis THrough Evolutionary Relationships) system (http://www.pantherdb.org; $\mathrm{Mi}$ et al., 2016). PANTHER software classifies genes and proteins by their functions, using published scientific experimental evidence and evolutionary relationships abstracted by curators with the goal of predicting function even in the absence of direct experimental evidence (Mi et al., 2010). Proteins are classified into families and subfamilies of shared function, which are then categorized using a highly gene controlled vocabulary (Gene Ontology terms) by biological process, molecular function and cellular localization (for the detailed methodology of Gene Ontology analysis, please refer to Data Sheet 1 in the Supplementary Material, a detailed description of these data is presented in the Supplemental Figures $1-3)$.

\section{BrdU and Proliferation Assay}

NSCs were plated onto poly-L-ornithine coated plates at $10^{5}$ /well (24-well plate). Twenty-four hours post plating, recombinant mouse VEGF-A (100 ng/ml, R\&D system) was added to culture medium and BrdU was added into culture $24 \mathrm{~h}$ later at a concentration of $10 \mu \mathrm{M}$ prior to fixation with $4 \%$ PFA. SU1498 was added into culture at 5 or $10 \mu \mathrm{M}$ prior to the addition of VEGF. The number of BrdU positive cells was quantified only in live cells.

\section{Statistical Analyses}

Data were expressed as mean \pm s.e.m. Statistical tests were carried out with one-way or two-way analyses of variance (ANOVAs) followed by post-hoc paired comparisons using the Fisher's PLSD test when appropriate (Statview 5.0.1, SAS Institute Inc., Cary, NC). Values of $p<0.05$ were considered as significant.

\section{RESULTS}

\section{Emx1 Gene Deletion Reduces Embryonic Neural Stem Cell Population}

Emx1 deletion is associated with the reduction of volume and immature neurons in the dentate gyrus (DG) of adult mice (Hong et al., 2007). To determine whether this abnormality originated from the early stage of brain development, neurosphere assay was performed with embryonic or adult brains from Emx1 knockout (KO) and wild type (WT) mice. Although embryonic brains from both genotypes formed neurospheres, the number of neurospheres or neuroprogenitor cells $(0.5 \mathrm{~mm}<$ diameter $<$ $1 \mathrm{~mm}$ ) in E14 $E m \times 1^{-/-}$forebrains was significantly less than those of $E m x 1^{+/+}$brains. In addition, the size of neurospheres was smaller, indicating that $E m \times 1^{-/-}$embryonic NSCs had a 


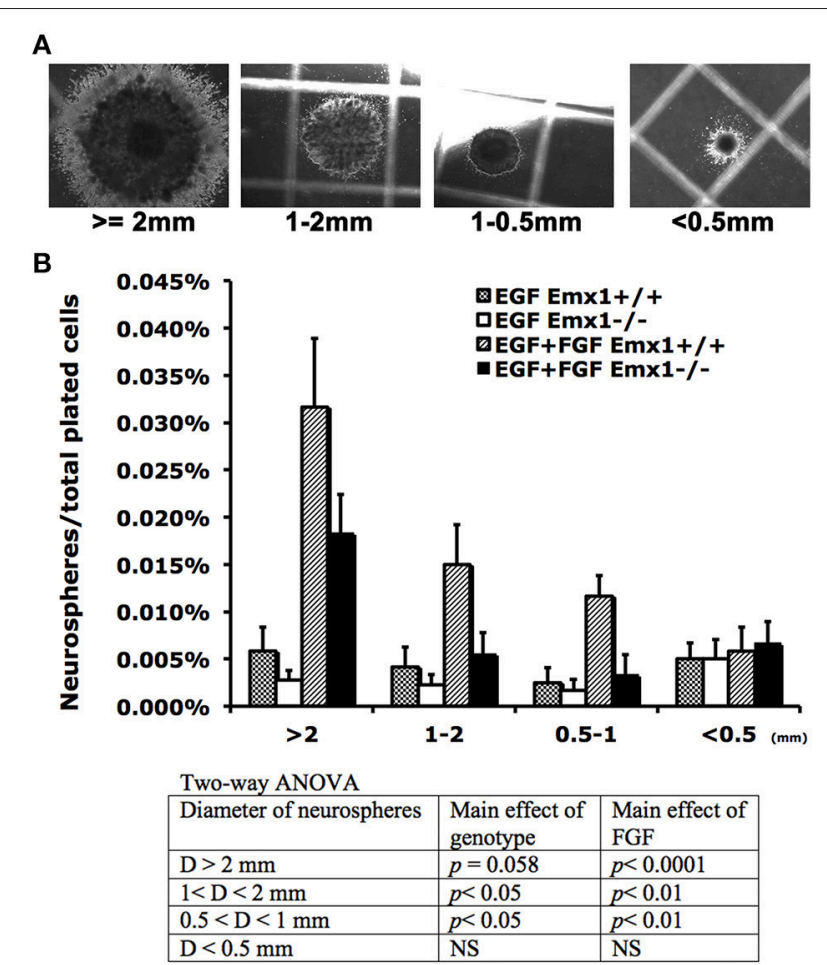

C

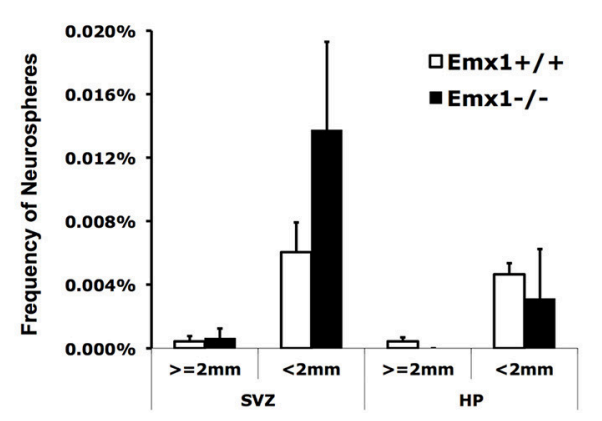

FIGURE 1 | The effect of homeobox gene Emx1 deletion on the formation of neurospheres in the embryonic and adult forebrains. Neurospheres grown on the semi-solid collagen plates were categorized into four groups according to size as indicated (A). Neurospheres that have a diameter of more than $2 \mathrm{~mm}$ are regarded as true neural stem cells and others are progenitor cells (Louis and Reynolds, 2010). (B) Neural colony forming cell assay demonstrates that $E m \times 1^{-/-}$embryonic forebrains formed significantly less neurospheres with sizes between 0.5 and $1 \mathrm{~mm}$ in diameter. The presence of FGF-2 $(20 \mathrm{ng} / \mathrm{ml})$ in the growth medium enhanced the genotype disparity in neurosphere formation. The $p$-values of the main effects of genotype and FGF following 2-way ANOVA are summarized as shown. Sample sizes for WT EGF, KO EGF, WT EGF+FGF, KO EGF+FGF are 4, 6, 4, 6, respectively. (C) The frequency of neurospheres per plated cells from the dissected subventricular zone (SVZ) or hippocampus (HP) in the adult forebrains cultured in the presence of EGF+FGF. There was no significant difference in the frequency of neurospheres from adult brain tissue between two genotypes. Unlike the embryonic brains, the adult brains have very few true neural stem cells ( $\geq 2 \mathrm{~mm}$ in diameter). $N=4-6$ brain samples/group for embryonic and 4-9 brain samples/group for adult neurosphere assay.

limited proliferative potential (Figures 1A,B). The frequency of neurospheres formed during 21 days of culture also differed depending on the presence of growth factors. There was a significant effect of FGF on the frequency of neurospheres greater than $0.5 \mathrm{~mm}$ in diameter in both genotypes (Figure 1). In contrast to the embryonic brains, the adult brains harbor very few true NSCs in either genotype. There was also no significant difference in the overall frequency of NSCs within the progenitor regions of subventricular zone or the hippocampus between genotypes (Figure 1C).

\section{Emx1 Gene Deletion Impairs the Self-Renewal Capacity of the Embryonic Neural Stem Cells}

Neurospheres contain multipotent NSCs with heterogeneous capacity in clonal expansion. To determine whether the observed difference in the number or size of neurospheres is attributed to differences in self-renewal capacity between genotypes, we quantified the number of secondary neurospheres generated by single primary neurospheres following 10 days of culture in a self-renewal assay. We found that primary neurospheres from forebrains of both Emx1 WT and KO embryos had the ability of self-renewal (Figure 2A), but differed in the extent of producing secondary neurospheres (Figure $\mathbf{2 B}$ ). The numbers of primary and secondary neurospheres from $E m x 1 \mathrm{KO}$ brains were significantly reduced to 30 and $50 \%$ of those from the Emx1 WT ones, respectively (Figure 2).

\section{Emx1 Gene Deletion Does Not Affect Neuronal or Glial Differentiation of NSCs In vitro}

To compare the extent of multipotency of NSCs derived from Emx1 WT and KO embryonic forebrains, cells from neurospheres of both genotypes were exposed to differentiation medium for 10 days. The majority of dissociated NSCs cultured as monolayer cells displayed immunoreactivity for nestin, a marker of neuroprogenitor cells, prior to the induction of differentiation (Figures 3A-D). Multipotency was demonstrated by differentiation into TuJ1-positive neurons, and GFAPpositive astrocytes. However, no difference was found in the differentiation ratio of neurons or astrocytes between Emx1 WT and Emx1 KO NSCs (Figure 3E).

\section{Emx1 Gene Deletion Reduces the Chemotactic Response of NSCs toward Serum or VEGF}

Neuroblasts migrate in close association with blood vessels and long-distance migration of neuroblasts was found in peri-infarct tissue in human stroke, implicating a role for VEGF or other angiogenic factors in neurogenesis and neuroblast migration. To quantify the chemotactic response of NSCs, a modified Boyden Chamber assay was used in the presence of FCS or chemokine VEGF $_{165}$ as chemoattractants. In response to $10 \%$ FCS, Emx1 WT NSCs exhibited a 2.1-fold increase in chemotaxis activity relative to Emx1 KO NSCs. When cultured in the presence of EGF, NSCs of either $E m x 1$ genotype failed to migrate in response to $\mathrm{VEGF}_{165}$ at 10 or $100 \mathrm{ng} / \mathrm{ml}$ (Figure 4A). In contrast, when cultured in the presence of EGF and FGF, VEGF 165 at $50 \mathrm{ng} / \mathrm{ml}$ was able to induce a robust migration of Emx1 WT NSCs 


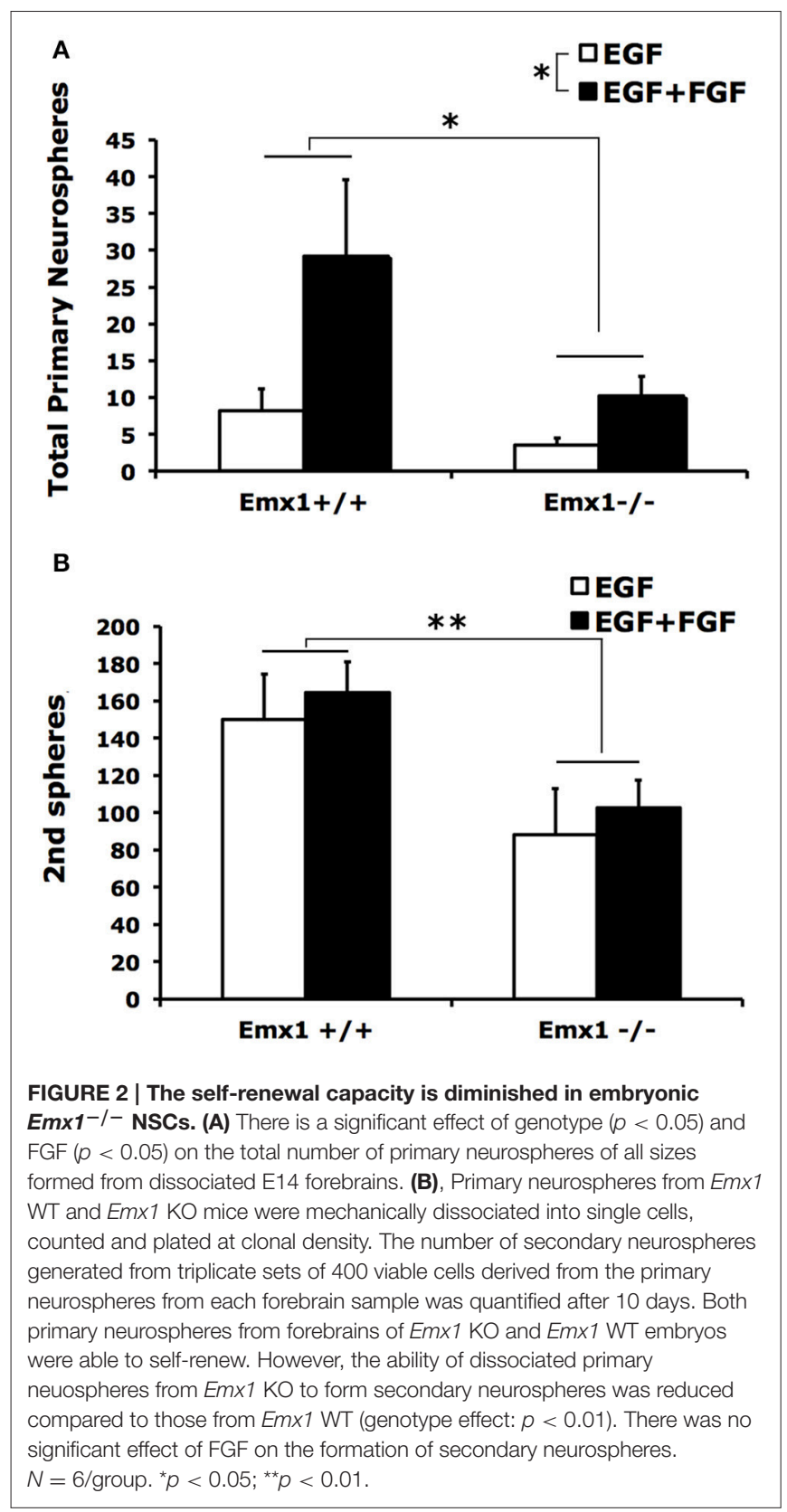

compared to Emx1 KO NSCs (Figure 4B). Out findings indicate that Emx1 gene deletion negatively impacted the chemotactic response of NSCs toward serum or VEGF, and the migration Emx1 WT NSCs induced by VEGF requires the presence of FGF in addition to EGF (Zhang et al., 2014).

\section{Proteomic Profiling Reveals Differences in the Protein Expression Pattern between Emx1 WT and KO NSCs}

Using tandem mass spectrometry, we analyzed a number of most distinctly different spots on the 2-D PAGE comparing the patterns of protein expression from the lysates of Emx1 WT and KO embryonic NSCs (Figure 5). Our neuroproteomics
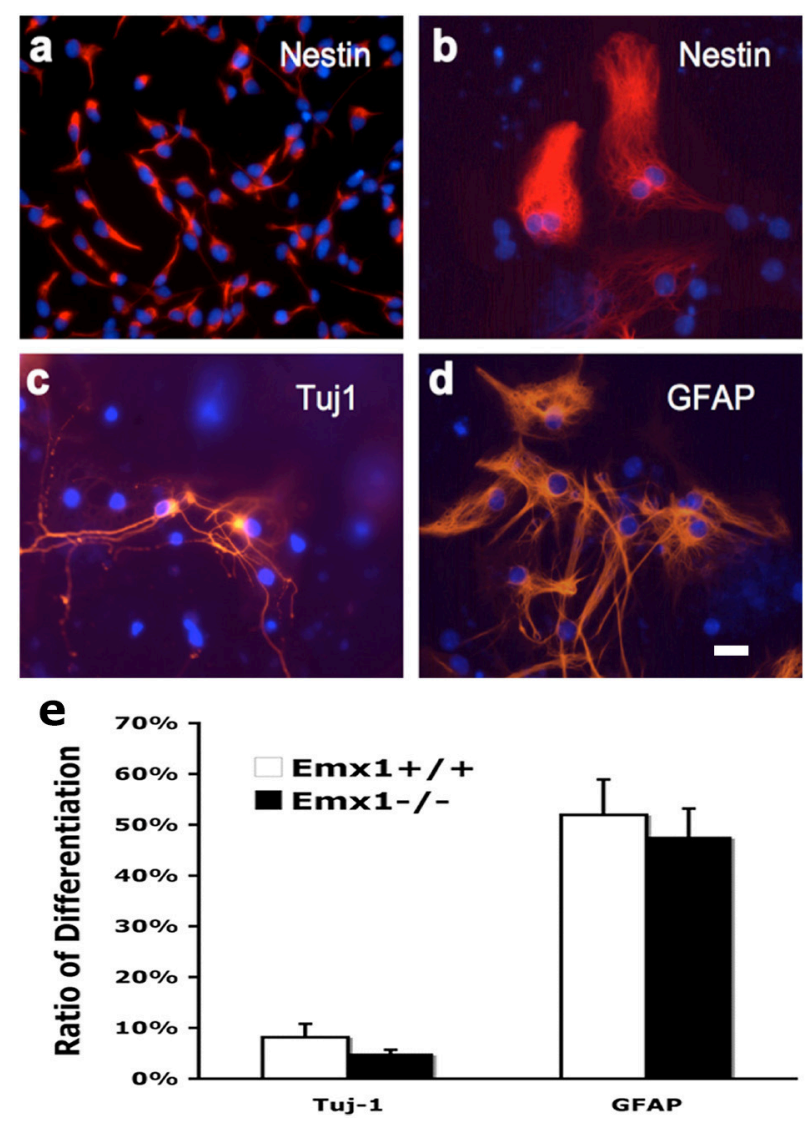

FIGURE 3 | Neuronal and glial differentiation from embryonic NSCs is not affected by Emx1 gene deletion. NSCs differentiate in response to growth medium containing differentiation supplement after 7-14 days. Representative photomicrographs showing undifferentiated neural stem cells grown as monolayer (Nestin; A, soon after seeding; B, 7 days after seeding), differentiated neurons (C, TuJ1) and glia (D, GFAP) in red and nuclei in blue (Hoechst). Bar graph indicated the quantitative results for differentiation. The extent of neuronal vs. glial differentiation was determined by counting 200 cells after staining with antibodies against TuJ1 and GFAP. No differences in the differentiation ratios of neurons and astrocytes between $E m \times 1^{+/+}$and Em $\times 1^{-/-}$group (E). Scale bar, $25 \mu \mathrm{m} . N=4$ NSC samples/group, and each NSC sample was plated in 3-4 wells.

analysis detected 38 differentially expressed proteins between $E m \times 1^{-/-}$and $E m \times 1^{+/+}$(see Table 1 for protein Ids and their respective biological functions). Detailed characteristics of each individual protein with its corresponding mass spectrometry data are included in Supplemental Tables 1,2 and Data Sheet 1 in the Supplementary Material.

\section{Global Interaction Map and Protein Cluster Analysis of the Emx1 Altered Proteome}

Based on the above neuroproteomics findings, we utilized a neurosystem biology platform for protein network and pathway analysis relevant to the altered proteins in the $E m \times 1^{+/+}$vs. $E m \times 1^{-/-}$NSCs. For this purpose, we utilized two bioinformatics analysis approaches: a global protein interaction and unsupervised pathway assessment on one side and cluster 


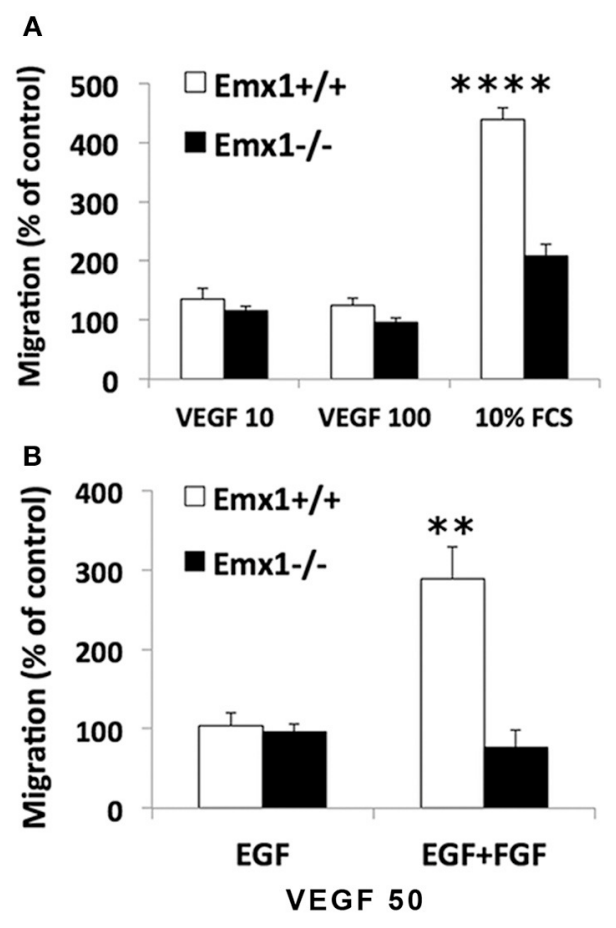

FIGURE 4 | Chemotactic response to serum or VEGF is reduced in Emx1-/- NSCs. (A) Emx1 KO NSCs exhibited a reduced chemotactic response to serum compared to Emx1 WT NSCs. The migratory response of E14 NSCs to fetal calf serum (FCS) and recombinant human VEGF165 were tested in a modified 96-well Boyden chamber assay when cells were cultured in medium containing EGF. Ten percent FCS induced a 4.4-fold (439 $\pm 19 \%)$ and 2.1 -fold $(209 \pm 19 \%)$ increase in migratory response in Em 1 1 WT and Emx1 KO NSCs, respectively. To the contrary, VEGF, either at 10 or $100 \mathrm{ng} / \mathrm{ml}$, stimulated very little migration of NSCs from either genotype. (B) FGF is necessary for the chemotactic response of Emx1 WT NSCs to VEGF. NSCs were cultured in medium containing either EGF alone or EGF+FGF. Chemotaxic response toward $50 \mathrm{ng} / \mathrm{ml}$ VEGF was detected in NSCs from Emx1 WT, but not from Emx1 KO, cultured in the presence of EGF+FGF. Values shown are mean \pm SEM and are expressed as percentage of the unstimulated basal migratory rate (control $=100 \%)$. ${ }^{* \star} p<0.01 ;{ }^{* \star \star \star} p<0.001$. $N=24-32 /$ group.

targeted approach for selective implicated functional biological pathways on the other hand.

For the targeted cluster analysis, selected Emx1-implicated pathways were assessed against Emx1-identified differential proteomic data. Using the SNEA algorithm, targeted enriched pathways revealed that several altered proteins were associated with Emx1 differential proteome-implicated neural pathways including: cell proliferation, cell migration, cell differentiation, cytoskeletal actin organization, and neuronal migration as illustrated in Figures 6A-E. For detailed cluster analysis in silico validation including statistical analysis, protein entity, biological process along with the interaction type and the PubMed reference utilized see Supplemental Tables 3A-C, 4A-C, 5A-C, 6A-C and Data Sheet 1 in the Supplementary Material.

For the global interaction and unsupervised pathway assessment, differential pathways were generated using the "direct interaction" algorithm to map the relationship among the identified proteins. We found that among the 38 altered proteins, 17 had direct regulatory function, including binding, post-translational modifications and transcriptional regulation. Unsupervised pathway assessment, showed that these proteins are implicated in several biological pathways involving brain development, axonal guidance, synaptic transmission, neurogenesis along with the hippocampal morphology biological process (highlighted in blue rectangles). Of interest, these altered proteins showed a centrality relation with VEGF protein being an upstream regulator for several of the Emx1-identified proteome involving Cofilin1, enolase, phosphatidyl-ethanolamine-binding protein, and neurite growth-promoting factor 2 (Figure 7). Statistical significance of the interaction was performed in silico for the validation process. A detailed depiction of these data is presented in the (Supplemental Tables 7A-C and Data Sheet 1 in the Supplementary Material). These include the protein entity and biological process involved along with the interaction type and directionality and the PubMed reference utilized to derive these interaction type. Due to the well-recognized central role of Cofilin 1 and its diverse interaction with several of the identified biological pathways, we performed a functional validation analysis to determine the expression of Cofilin $1 / \mathrm{p}$-Cofilin 1 in the NSCs of both genotypes in response to VEGF signaling.

\section{Emx1 KO NSCs Display Reduced Level of p-Cofilin1 Expression}

To further determine whether Cofilin1 plays a role in VEGF signaling, lysates of NSCs from both genotypes stimulated with VEGF or media were analyzed by western blotting for the expression of p-Cofilin1, total Cofilin1, and VEGF RECEPTOR 2 FLK. We found that Emx1 KO NSCs had significantly reduced p-Cofilin 1 compared to those from Emx1 WT, when cultured in medium containing EGF only or EGF+FGF (Figures 8A,B). VEGF further increased the level of $\mathrm{p}$-Cofilin only in the WT NSCs (Figures 8A,B). VEGF also modestly induced the expression of FLK only in the WT NSCs (Figures 8A,C). Our results suggest that Emxl gene deletion reduces phosphorylated Cofilin1, likely contributes to the difference in neurogenesis and chemotactic response to VEGF.

Because VEGF receptors are expressed in NSCs (Maurer et al., 2003) and VEGF stimulates the expansion of NSCs in vitro (Schänzer et al., 2004), we determine the effect of VEGF on the proliferation and survival of NSCs. We found that VEGF-A $(100 \mathrm{ng} / \mathrm{ml})$ significantly increased the percentage of BrdU immunoreactive cells already after $4 \mathrm{~h}(p<0.05)$ of treatment. The effect was even more pronounced after $17 \mathrm{~h}$ $(p<0.001$; Supplemental Figure 1A and Data Sheet 1 in the Supplementary Material). In addition, VEGF-induced NSC expansion was dose dependently reduced by the specific VEGF RECEPTOR 2 antagonist SU1498 (Supplemental Figure 1B and Data Sheet 1 in the Supplementary Material), suggesting that VEGF increased the number of NSCs possibly by stimulating proliferation or enhancing their survival.

\section{DISCUSSION}

Existing literature suggests that the Emx1 transcription factor is not among the most critical players in mammalian brain 


\section{EMX-1 +/+}

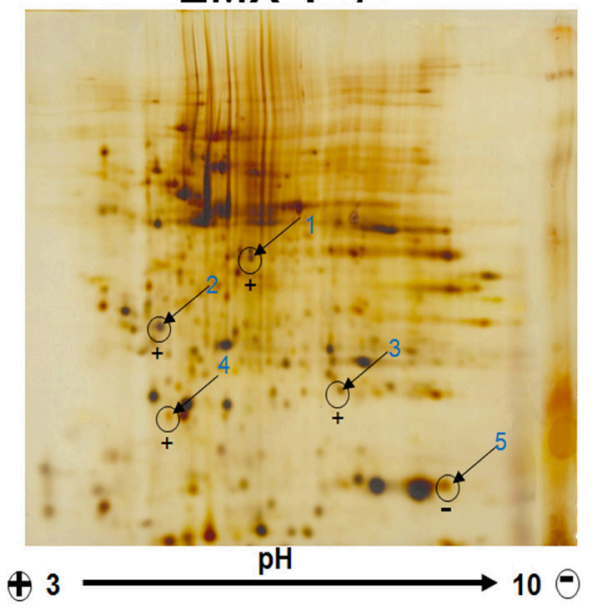

EMX-1 -/-

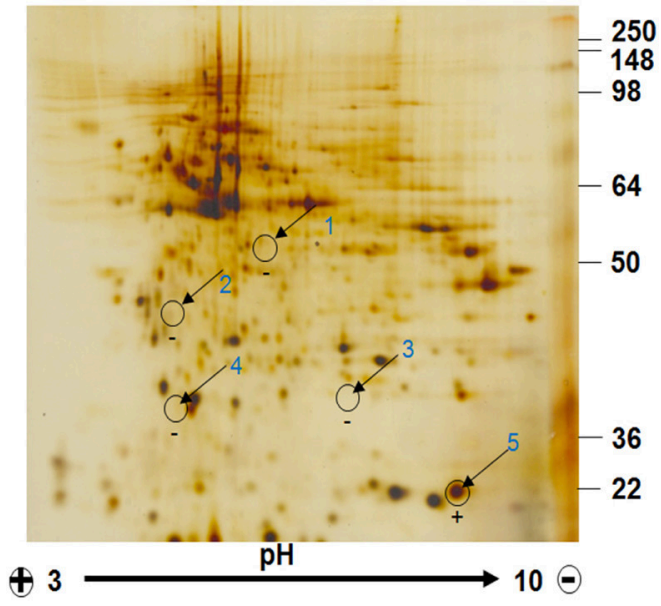

FIGURE 5 | Two-Dimensional Gel Electrophoresis proteomic profiling of Emx1 +/+ and Emx1-/- NSCs. Differential comparative proteome profile from $E m \times 1^{+/+}$and $E m \times 1^{-/-}$NSCs lysates was compared and visualized by silver staining. Comparative Coomassie stain performed on gels was used for spot cutting. Five most apparent spots showing differential expression level between genotypes were labeled and excised for protein identification by tandem MS/MS analysis. Spot \#5 was identified as Cofilin through Swiss-Prot Protein Knowledgebase.

development since the Emx1-single mutant was not only viable but also without any severe CNS phenotype in contrast to the mutations caused by a number of other genes (Patarnello et al., 1997; Guo et al., 2000; Bishop et al., 2002, 2003; Cao and Li, 2002; Muzio and Mallamaci, 2003; Shinozaki et al., 2004; Tamamaki, 2005; von Frowein et al., 2006; Piper et al., 2007; Cocas et al., 2009; Sen et al., 2013). The role of Emx1 during brain development was first implicated in axon guidance, regulating midline crossing of an axonal subpopulation of the corpus callosum derived from the anterior cingulate cortex (Lim et al., 2015). Apart from an acallosal phenotype, the adult Emx1 null mice also exhibited smaller dentate gyri and reduced neurogenesis (Hong et al., 2007). However, it is unclear whether the reduced dentate gyrus is attributed to defective signaling in neurogenesis. By comparing the frequency of neurosphere formation between the WT and KO Emx1 forebrains, we found that the embryonic but not adult Emx1 KO brains had significantly fewer NSCs and neuroprogenitor cells, suggesting that Emx1 was involved in neurogenesis at least during early brain development. The deletion of the Emx1 gene also negatively impacted the selfrenewal capacity of isolated NSCs, diminishing their chemotactic response to FCS or VEGF, but it did not affect neuronal or glial differentiation. Comparative proteomics revealed that the altered proteins from Emx1 KO NSCs participated in many aspects of brain development, including axonal guidance and neurogenesis, through interaction with VEGF. Cofilin 1 exists in balance with its phosphorylated form in the VEGF signaling pathway. Emx1 KO NSCs appeared to have significantly reduced level of p-Cofilin1 compared to Emx1 WT NSCs. Additionally, VEGF further increased p-Cofilin 1 only in the latter. To the best of our knowledge, this is the first study demonstrating the role of Emx1 in neurogenesis and the effect of Emx1 gene deletion on Cofilin1 phosphorylation utilizing proteomics platform.
Not surprisingly, the neurosphere assay results indicate that the adult brains harbor significantly fewer neuroprogenitor cells compared to embryonic brains, regardless of Emxl genotype. It appears that only the embryonic brains contain a significant amount of true NSCs that can be propagated in many generations in vitro, while the adult brains have a number of neurospheres that are $>2 \mathrm{~mm}$ in diameter. The presence of FGF increases the frequency of neurospheres $>0.5 \mathrm{~mm}$ in diameter from embryonic brains of both genotypes. A previous report suggests that stem/precursor cells in the embryonic cortex can be very diverse in regards to their signaling property. Linear progression of the precursor cells to an EGF-responsive state can be promoted by FGF among other factors (Lillien, 2014), which is consistent with our observation. There also exists a rostral-caudal gradient of Emx1-lineage precursors, with more cells rostrally. We did not determine the rostral-caudal relationship in the abundance of precursor cells in the embryonic brains due to the small size; however, data from the adult neurosphere assay seem to agree with this finding, as the SVZ tended to produce more neurospheres than the hippocampus. Data from the self-renewal assay suggest that Emx1 KO precursors likely do not respond as well to EGF or FGF signaling to form primary or secondary neurospheres. Apart from its key role in neurogenesis and NSC self-renewal, Emx1 also contributes to other aspects of brain development such as cortical patterning (Stocker and O'Leary, 2016) and regional fate determination (Chou et al., 2009) via the complex interplay between $E m x 1$ and other genes.

A proteomic search using 2-D gel electrophoresis coupled with tandem mass spectrometry revealed the differential expression of at least 38 proteins between WT and KO NSCs. These protein hits were assessed via a targeted approach to study their relationship in already established pathways implicating Emxl's role in neurogenesis, and the details 
TABLE 1 | Differentially altered proteins and their functional ontology between $E m \times 1^{+/+}$and $E m \times 1^{-/-}$NSCs as identified from spots on the 2-D gel.

\begin{tabular}{|c|c|c|}
\hline Spot No. & Protein name & Functional ontology \\
\hline \multirow[t]{2}{*}{1} & Phosphoglycerate kinase & - A protein kinase involved in glycolysis. \\
\hline & & - Loss of function mutation (deficiency) causes chronic hemolysis with or without mental retardation (Beutler, 2007). \\
\hline \multirow[t]{2}{*}{1} & Alpha-enolase & - A protein involved in glycolysis pathway. \\
\hline & & $\begin{array}{l}\text { - This protein acts as an autoantigen in Hashimoto encephalopathy and used as a marker for hypoxic brain injury } \\
\text { (heterodimeric form) after cardiac arrest (Ochi et al., 2002; Rech et al., 2006). }\end{array}$ \\
\hline 1 & mitochondrial & $\begin{array}{l}\text { - The inheritance of a mutated form causes chorioretinal atrophy that can progressively lead to blindness, but } \\
\text { patients generally have normal intelligence. }\end{array}$ \\
\hline 1 & Tubulin beta-2A chain & $\begin{array}{l}\text { - Tubulin is the principle component of microtubules that involve in many processes. Mutation in this gene causes } \\
\text { brain malformation that affects neuronal migration and axonal guidance (Cushion et al., 2014). }\end{array}$ \\
\hline
\end{tabular}

\begin{tabular}{ll}
\hline Nucleoporin Nup37 & It is a component of the nuclear pore complex (NPC) that is required for its proper assembly and function. It is also \\
& essential for the attachments of microtubules to kinetochores.
\end{tabular}

$1 \quad$ Pyruvate kinase isozymes M1/M2 - A glycolytic enzyme that catalyzes the final step of glycolysis (rate limiting step) and generates ATP by transferring
2 14-3-3 protein epsilon - An adapter protein that has the ability to bind to a large number of proteins that are implicated in different signaling pathways.
2 14-3-3 protein zeta/delta - An adapter protein that has the ability to bind to a large number of proteins. The binding occurs by the recognition of a phosphoserine or phosphothreonine. It plays an important role in cell survival and apoptosis.
2 14-3-3 protein theta - An adapter protein that has the ability to bind to a large number of proteins that are implicated in different signaling pathways.

\begin{tabular}{|c|c|c|}
\hline 3 & $\begin{array}{l}\text { ATP synthase subunit alpha, } \\
\text { mitochondrial }\end{array}$ & $\begin{array}{l}\text { - A mitochondrial ATP synthase, a membrane bound protein that drives the formation of ATP by harnessing the } \\
\text { energy from protons gradient. }\end{array}$ \\
\hline 3 & $\begin{array}{l}\text { ATP synthase subunit O, } \\
\text { mitochondrial }\end{array}$ & $\begin{array}{l}\text { - A mitochondrial ATP synthase, a membrane bound protein that drives the formation of ATP by harnessing the } \\
\text { energy from protons gradient. }\end{array}$ \\
\hline 3 & $\begin{array}{l}\text { ADP-ribosylation factor-like } \\
\text { protein } 3\end{array}$ & $\begin{array}{l}\text { - A small GTP-binding protein that can exist in two states: GTP-binding (active) and GDP-binding (inactive). It is } \\
\text { required for normal cytokinesis and cilia signaling. }\end{array}$ \\
\hline 3 & Peroxiredoxin-1 & $\begin{array}{l}\text { - An antioxidant protein that participates in the elimination of peroxides from the cell. Additionally, it might play a role } \\
\text { in the signaling cascades of growth factors and tumor necrosis factor-alpha. }\end{array}$ \\
\hline 3 & Tetratricopeptide repeat protein 25 & - No known function. \\
\hline 4 & $\begin{array}{l}\text { Heterogeneous nuclear } \\
\text { ribonucleoprotein } \mathrm{K}\end{array}$ & $\begin{array}{l}\text { - A pre-mRNA binding protein that has an affinity toward poly C (cytidine) sequence. It plays a role pre-mRNA } \\
\text { metabolism and processing and participates in p53/TP53 response to DNA damage, acting at the level of both } \\
\text { transcription activation and repression. }\end{array}$ \\
\hline
\end{tabular}




\section{TABLE 1 | Continued}

\begin{tabular}{lll}
\hline Spot No. & Protein name & Functional ontology \\
\hline 4 & Tubulin beta-2C chain & $\begin{array}{r}- \text { Tubulin is the major constituent of microtubules. It binds two moles of GTP, one at an exchangeable site on the } \\
\text { beta chain and the other at a non-exchangeable site on the alpha chain. }\end{array}$ \\
\hline 4 & $\begin{array}{l}\text { Phosphatidylethanolamine-binding } \\
\text { protein 1 }\end{array}$ & - It binds to different molecules including ATP, opioids and phosphatidylethanolamine. \\
\hline Proteasome subunit beta type-6 & $\begin{array}{l}\text { - The proteasome is a protein complex that acts as a proteinase and has the ability to cleave peptides with very } \\
\text { broad specificity that include peptide bonds with Arg, Phe, Tyr, Leu, and Glu adjacent to the leaving group at } \\
\text { neutral or slightly basic pH. It is ATP-dependent. }\end{array}$
\end{tabular}

$4 \quad$ NudC domain-containing protein 2 - This protein may regulate the LIS1/dynein pathway by stabilizing LIS1 with Hsp90 chaperone.

$4 \quad$ Ras-related protein Rap-2a - A small GTP-binding protein. Rap-2a has a role in different signaling cascades that regulate cytoskeleton, cell 4 migration, cell adhesion and cell spreading. It is a part of a signaling complex that regulates neuronal dendrite extension and arborization during development.

$4 \quad$ Tubulin alpha-1A chain - Tubulin is the major constituent of microtubules. It binds two moles of GTP, one at an exchangeable site on the beta chain and the other at a non-exchangeable site on the alpha chain.

$4 \quad$ F-actin-capping protein subunit alpha-1

- F-actin-capping proteins bind to the fast growing ends of actin filaments (barbed end) independently of calcium, thus blocking the exchange of subunits at these ends. In contrast to other capping proteins, these proteins do not sever actin filaments.

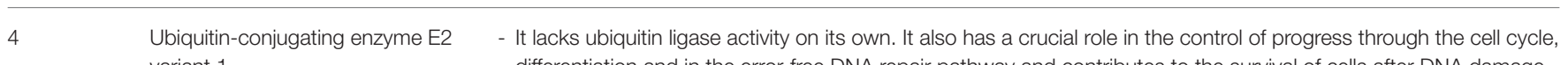
variant $1 \quad$ differentiation and in the error-free DNA repair pathway and contributes to the survival of cells after DNA damage.

\begin{tabular}{|c|c|c|}
\hline 5 & $\begin{array}{l}\text { Glyceraldehyde-3-phosphate } \\
\text { dehydrogenase }\end{array}$ & - A glycolytic enzyme that catalyzes the first step of the pathway. \\
\hline 5 & ADP-ribosylation factor 1 & $\begin{array}{l}\text { - A GTP-binding protein that has an ADP-ribosyltransferase activity. It activates cholera toxin and plays a role in } \\
\text { intracellular trafficking. }\end{array}$ \\
\hline 5 & Destrin & $\begin{array}{l}\text { - An actin-depolymerizing protein. It binds to actin monomers and breaks off actin filaments (F-actin) in a } \\
\text { pH-independent manner. }\end{array}$ \\
\hline
\end{tabular}
$5 \quad$ Peroxiredoxin-5, mitochondrial - An antioxidant protein that reduces hydrogen peroxide and alkyl hydroperoxides in the cell and is involved in intracellular redox signaling.
$5 \quad N(G), N(G)$-dimethylarginine $\quad$ - It hydrolyzes N(G),N(G)-dimethyl-L-arginine (ADMA) and N(G)-monomethyl-L-arginine (MMA) with a role in nitric dimethylaminohydrolase $1 \quad$ oxide generation through the inhibition of NOS.
5 Cofilin-1 - It regulates actin cytoskeleton dynamics through binding to F-actin in a PH dependent manner, playing a major role in the regulation of cell morphology and cytoskeletal organization. It is also important for the progression to mitosis and cytokinesis.

\begin{tabular}{lll}
\hline 5 & Cofilin-2 & $\begin{array}{l}\text { It controls both actin polymerization and depolymerization in a reversible and pH-sensitive manner. It has the ability } \\
\text { to bind G- and F-actin and is an essential component of the intranuclear as well as cytoplasmic actin rods. }\end{array}$ \\
\hline 5 & $\begin{array}{l}\text { Peptidyl-prolyl cis-trans } \\
\text { isomerase A }\end{array}$ & $\begin{array}{l}\text { A PPlases catalyzes the cis-trans isomerization; it increases the folding rate of different proteins and regulates } \\
\text { many biological Processes including cellular signaling, apoptosis and inflammation. }\end{array}$
\end{tabular}

\begin{tabular}{lll}
\hline 5 & Peptidyl-prolyl cis-trans & A PPlases catalyzes the cis-trans isomerization of proline imidic peptide bonds in oligopeptides. It has been \\
isomerase H & shown that PPIH participates in pre-mRNA splicing and it might act as a chaperone.
\end{tabular}
$5 \quad$ Nucleoside diphosphate kinase A - An enzyme that catalyzes the transfer of phosphate from ATP to the NDP beta phosphate via a ping-pong mechanism. It plays a role in cell proliferation, differentiation, development, signal transduction and gene expression. It is necessary for neural development including neural patterning and cell fate determination.

We utilized Uniprot database to extrcat protein functions (http://www.uniprot.org/uniprot/). 


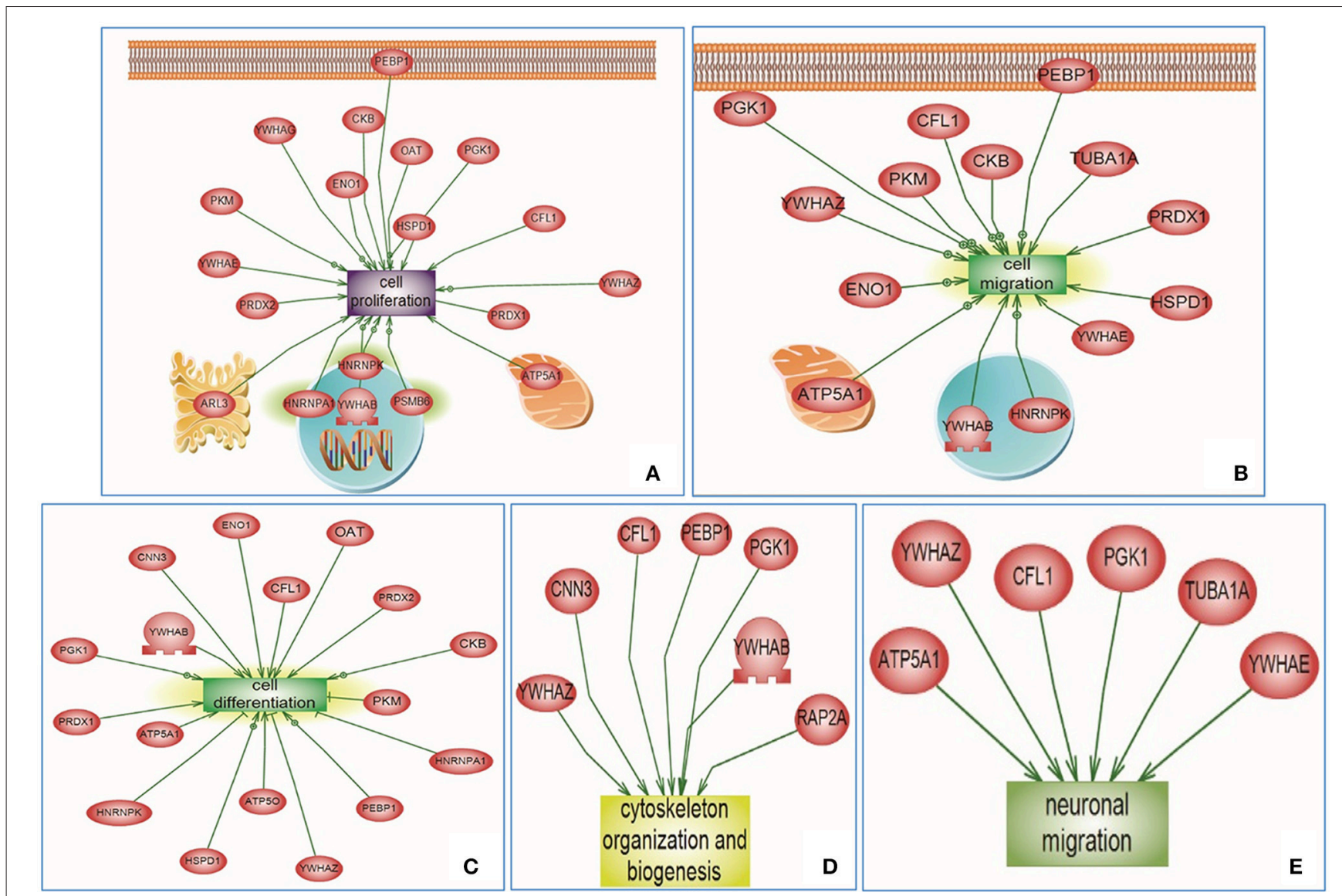

FIGURE 6 | Altered Emx1-related protein cluster analysis extracted from the Sub Network Enrichment Analysis (SNEA) Algorithm. Subnetwork Enrichment Pathway Analyses and statistical testing for the entire altered Emx1 proteome was analyzed using the SNEA algorithm to identify unique biological clusters of differential proteins. Several proteins were clustered under certain functional classes, such as cell proliferation, cell migration, cell differentiation, cytoskeletal organization, and neuronal migration (Clusters $\mathbf{A}-\mathbf{E}$ ). In silico cluster analysis validation including the protein Entity and biological process involved along with the interaction type and directionality and the PubMed reference utilized to derive these interaction type are presented in Supplemental Tables 3A-C, 4A-C, 5A-C, 6A-C and Data Sheet 1 in the Supplementary Material. The shape of a given protein is indicative of its functional class as shown in the legend (rectangular shapes indicate the biological process) \& (the elliptical shape indicates the proteins). Also included in the legend is the directionality relation of the protein with the corresponding biological process (arrow head).

regarding their molecular function, biological process and cellular locationization are shown in Supplemental Figures 2-4. Among the proteins identified, OAT, Cofilin1, 14-3-3 beta protein, Creatine Kinase B-type Peroxiredoxin 2, Peroxiredoxin 1 , and HNRNPA1 were implicated in the cell differentiation process (Figure 6, Supplemental Tables 3A-C and Data Sheet 1 in the Supplementary Material). This is in agreement with what has been identified in a similar proteomics study performed on neural differentiation of human embryonic stem cells utilizing 2D-DIGE at three different stages early neural differentiation, neural ectoderm and mature neurons. Ten members of the peroxiredoxin (PRDX) family were upregulated in the different stages of differentiation, thus highlighting a link between neural differentiation and the redox process (Hoffrogge et al., 2007; Fathi et al., 2014). Indeed, the work of Novitch and Butler highlighted the role of Prdx1 along with the GDE2 protein in mediating a thiol-redox reaction involved in the process neural regeneration process (Novitch and Butler, 2009). Other altered pathways identified included cellular migration and proliferation involving a number of proteins including Cofilin1, YWHAE, ATP5A1, TUBA1A, PRDX1, ADP-ribosylation factor-like 3, and ENO1 among others (Figure 6, Supplemental Tables 4A-C, 5A-C and Data Sheet 1 in the Supplementary Material). The enolase protein has been shown to promote cell migration in the context of cancer (Yu et al., 2010; Hsiao et al., 2013). Similarly, the brain specific creatine kinase protein involved in cellular energetics, has been correlated with loss of neural cell circuits function upon downregulation; however, its contributes a part to local cytoskeletal dynamics promoting cell migration via lamellipodia formation (Kuiper et al., 2009). The role of ADP-ribosylation factor-like 3 has been recently studied as an indirect mediator of cell proliferation and neurogenesis via binding to the signal transducer and activator of transcription 3 (Togi et al., 2016). Our data also corroborate with the finding of a pro-survival role of ADP- ribosylation factor-like-3 protein in neural progenitor cells (Zhou et al., 2013). 


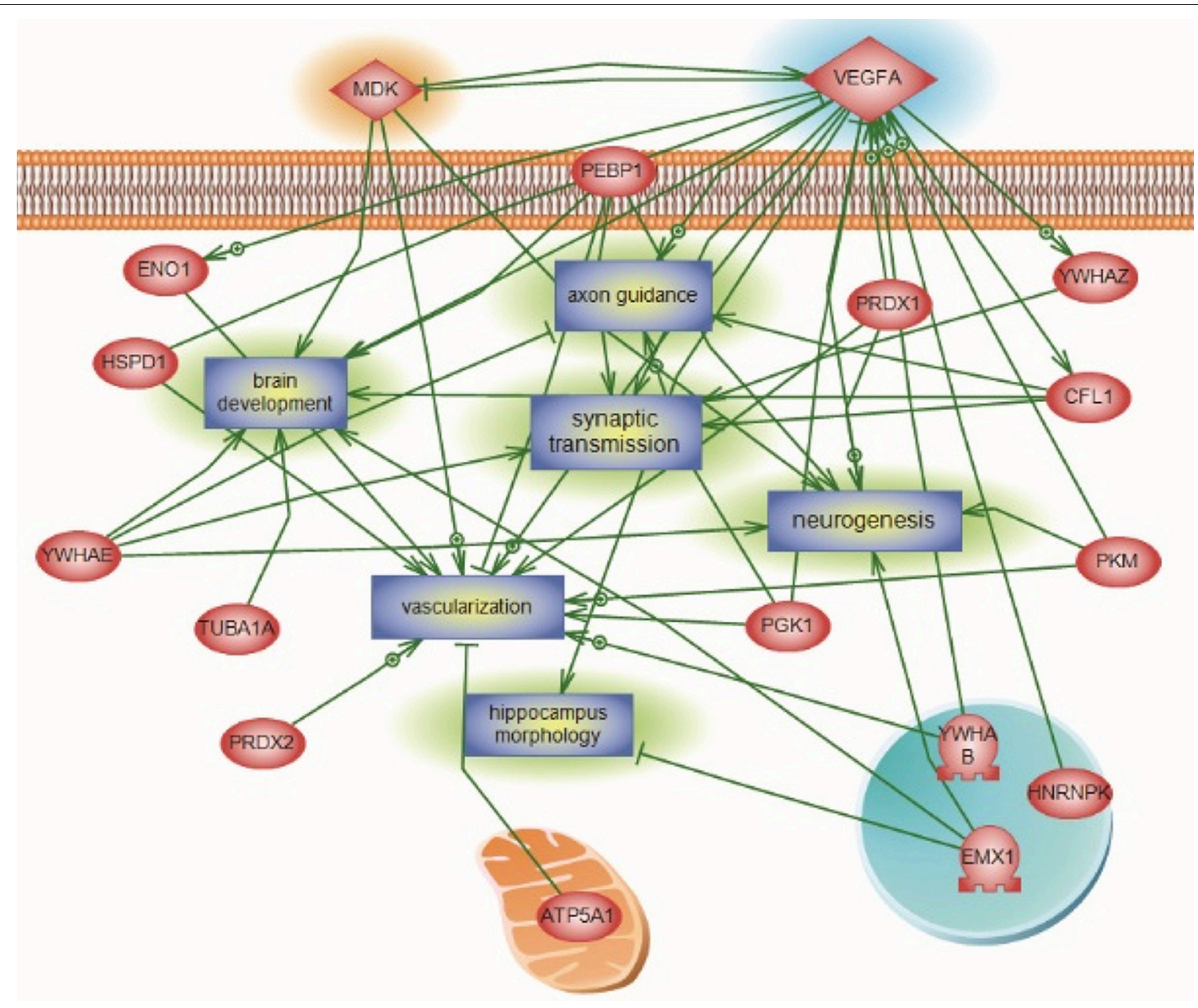

FIGURE 7 | Global Interaction Map and differential regulatory pathways of the Emx altered proteome. Altered Emx1-identified proteins are highlighted in light pink. Seventeen out of the 38 proteins had direct regulatory relationships, including binding, post-translational modifications, and transcriptional regulation. Differential pathways were generated using the "direct interaction" algorithm to map interaction and relationships. Based on Biological Process analysis and molecular functions, these proteins are implicated in brain development, axonal guidance, synaptic transmission, neurogenesis along with the hippocampal morphology biological process (highlighted as rectangles). VEGF-A was identified as the upstream regulator of the represented processes, intertwined with Cofilin1 and Emx1. In silico validation including the protein Entity and biological process involved along with the interaction type and directionality and the PubMed reference utilized to derive these interaction type are presented in Supplemental Tables 7A-C and Data Sheet 1 in the Supplementary Material.

In addition, cytoskeleton organization and biogenesis of biologically related proteins were shown to be among the major protein families to be altered in the context of Emx1 deletion. These include Cofilin1, calponin, destrin, and F-actincapping protein subunit alpha-1 proteins (refer to Table 1, Figure 6, and Supplemental Tables 6A-C and Data Sheet 1 in the Supplementary Material). Also of interest, these groups of proteins involve actin-binding activity implicated in cell motility. Calponin protein expression has been suggested to be involved in neural cell contractility, proliferation, and migration (Represa et al., 1995; Ferhat et al., 1996; Ulmer et al., 2013). Similarly, destrin is also an actin-depolymerizing protein, which is closely related to Cofilin1 (Hatanaka et al., 1996) with a similar peptide sequence to the ADF (actin depolymerizing factor) protein (Hawkins et al., 1993), which is implicated in the regulation of neural crest cell migration (Vermillion et al., 2014). Along the same line, among the altered proteins Tubulin protein family including Tubulin $\alpha$ and Tubulin $\beta$ (2a and 2c) also appears in high abundance (Supplemental Table 1 and Data Sheet 1 in the Supplementary Material). Tubulins play a key mechanical role in neuronal proliferation and migration during cortical development (Barkovich et al., 2012; Cushion et al., 2014). Both $\alpha$ - and $\beta$-Tubulin protein family bind and assemble microtubule polymers, forming the essential cytoskeletal structure during brain development with specific functions include facilitating neuronal communication by generating axonal fibers away from the cell body; as well as in assisting neuroblast proliferation and migration from the SVZ to developing neocortex (Desai and Mitchison, 1997; Dehmelt and Halpain, 2004, 2005; Guzik and Goldstein, 2004) The critical role of tubulin gene family is highlighted in the mutation studies identified in the neuronal specific $\alpha$ - and $\beta$-tubulin gene affecting the cortex, corpus 


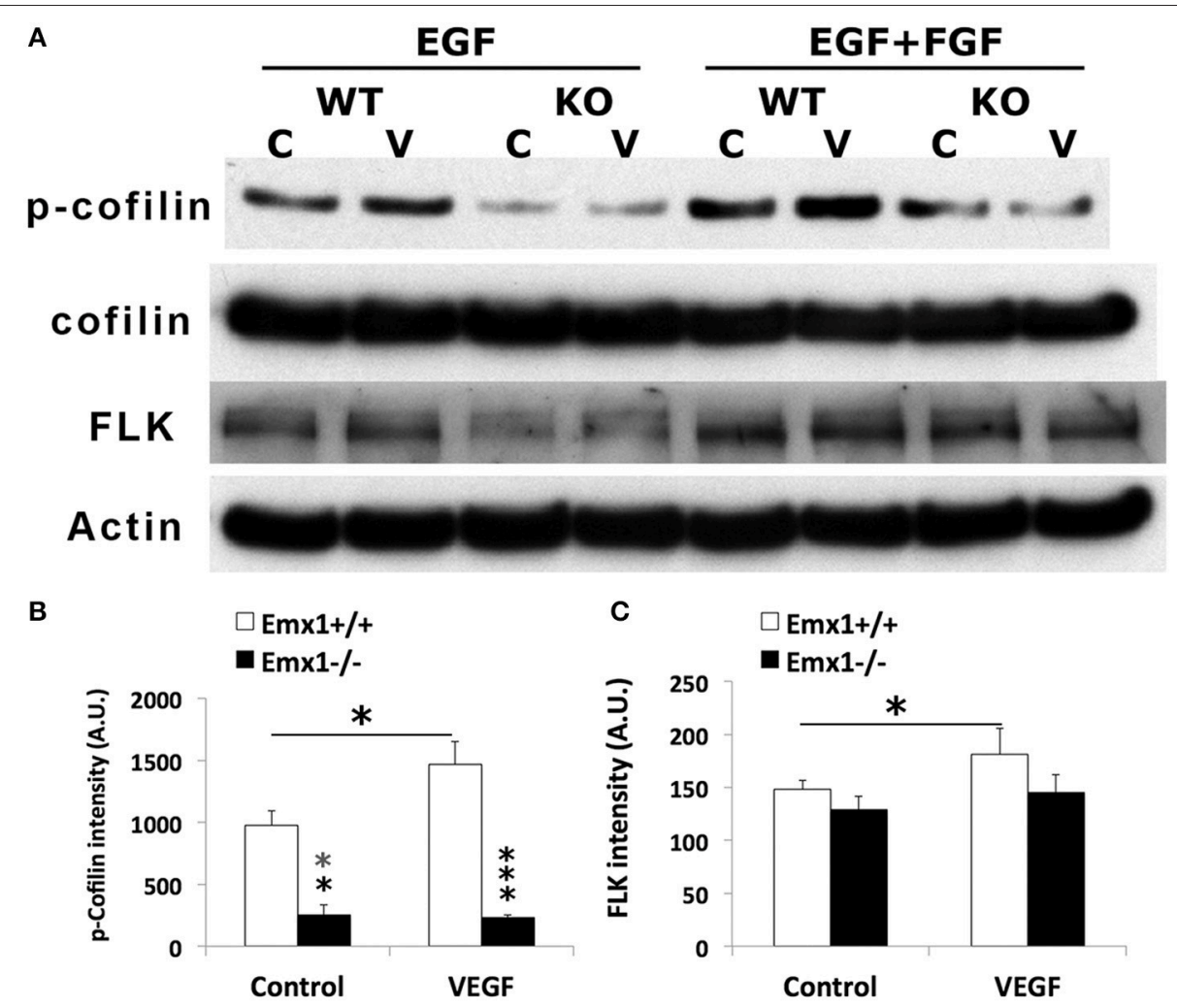

FIGURE 8 | VEGF induces Cofilin1 phosphorylation in Emx1+/+ NSCs. (A) Western blot analysis of NSC lysates for p-Cofilin1, Cofilin1, VEGF receptor 2 FLK and actin from both Emx1 genotypes treated with VEGF (V) $(50 \mathrm{ng} / \mathrm{ml})$ or medium (C) for $1 \mathrm{~h}$ in the presence EGF, or EGF+FGF as indicated. VEGF increased the level of $\mathrm{p}$-Cofilin1 in the Emx1+/+ NSCs cultured in EGF or EGF+FGF, compared to those treated with medium $\left({ }^{*} p<0.05\right)$. In contrast, Emx1-/- NSCs expressed significantly less amount of $p$-Cofilin1 whether in the absence $\left({ }^{* *} p<0.01\right)$ or presence of VEGF $\left({ }^{\star * *} p<0.005\right)$, compared to that of the Emx1+/+ NSCs (B). VEGF increased FLK expression only in the Emx1+/+ NSCs $\left(\mathbf{C},{ }^{*} p<0.05\right) . N=3$ /group.

callosum as well as basal ganglia (Kumar et al., 2010; Barkovich et al., 2012; Cushion et al., 2013, 2014; Amrom et al., 2014). In one proteomic study assessing temporal synaptic plasticity induced by $\mathrm{GABA}_{\mathrm{A}}$ receptor blockade, Tubulin $\beta$-2A protein regulated dendritic spine morphology and synaptic plasticity in the hippocampus (Jaworski et al., 2009). Another elegant recent study indicated that there existed an interaction of the Collapsin Response Mediator Protein (CRMP) family, CRMP2 and CRMP4 in particular, with tubulin and actin proteins in vitro that appeared to mediate growth cones development (Tan et al., 2015). This newly identified interaction is of high importance, considering the role of CRMP family in mediating cell migration, differentiation, neurite extension, and axonal regeneration in the developing nervous system, (Yoshimura et al., 2005; Ip et al., 2014). Our data suggest that Tubulin $\alpha$ and Tubulin $\beta$ (2a and $2 \mathrm{c}$ ) were upregulated in the $E m \times 1^{-/-}$NSCs, possibily attributable to be a feedback mechanism to counter balance the potential pathological phenotype of Emx1 deletion, although further experiments are warranted to ascertain this hypothesis.

Of special interest to us were the down regulation of p-Cofilin 1 protein in the $E m \times 1^{-/-}$NSCs and the diverse involvement of Cofilin1 in several of the targeted biological pathways as well as in the global interaction map (Figures 6, 7; respectively).
Neuronal migration and neurite outgrowth are highly regulated processes that both depend on the assembly and disassembly of F-actin via the formation of appropriate connections within the neural network. In vivo, the length of the actin filament can be regulated by members of the Cofilin 1 family of actin filament depolymerizing factors. Cofilin1, a downstream target of Rho kinase, is an actin-binding protein known to orchestrate actin filament turnover and regulate neuronal migration and neurite outgrowth (Carlier et al., 1997; Meberg, 2000; Meberg and Bamburg, 2000). Cofilin1 has also been shown to regulate cell cycle progression during cortical development (Bellenchi et al., 2007). The loss of Cofilin1 leads to the depletion of the ventricular zone neuronal progenitor pool and reduced cortical layer formation (Bellenchi et al., 2007). Aberrant expression of Cofilin1 might also underlie the defective development and cell migration in the telencephalon of Emx2 mutants ( $\mathrm{Li} \mathrm{H}$. et al., 2006).

VEGF also enhances axonal outgrowth by signaling through the Rho family of GTPases and their effector serine/threonine kinases, leading to downstream Cofilin1 phosphorylation (Jin et al., 2006; Zhang et al., 2011). However, we are uncertain whether the defect in Emx1 KO NSC migration toward VEGF or other factors in the serum is related to the defective 
midline crossing of axons that resulted in the observed acallosal phenotype in the Emx1 mutant. Interestingly, the disruption of interhemispheric connection in the naive $E m x 1 \mathrm{KO}$ mice did not significantly affect gross motor coordination nor learning and memory. However, it impaired fine motor function such as performance in the skill reaching task and reduced training induced neurogenesis (Hong et al., 2007). P-Cofilin1, on the other hand, regulates both cell proliferation and axon growth by promoting actin polymerization and cytoskeletal rearrangement. It is not surprising that training may lead to angiogenesis and the release of VEGF in addition to other growth factors that activate signals for neurogenesis in the WT, but less so in the KO mice due to an imbalance between Cofilin 1 and p-Cofilin 1 in the latter.

The VEGF receptor tyrosine kinase FLK-1, previously shown to be expressed in endothelial cells, is also expressed in neural progenitor cells of the mouse retina (Yang and Cepko, 1996) and embryonic forebrain NSCs (current study). Thus, VEGF signaling through FLK plays a dual role in neurogenesis and angiogenesis during development. In the adult brain, the coupling between angiogenic blood vessels and neuroblasts further supports a neurovascular niche in the post stroke microenvironment (Ohab and Carmichael, 2008), suggesting that ischemic brain injury induces signals recapitulating those during brain development. One of the most important and well studied growth factors that regulate post stroke neurogenesis and angiogenesis is VEGF. Both exogenous VEGF and stroke-induced endogenous VEGF promote neurogenesis (Sun et al., 2006), while the blockade of endogenous VEGF receptor downregulates neurogenesis (Bao et al., 1999). Despite the impaired VEGF signaling and reduced neurogenesis in the Emx1 KO mice, ischemic stroke with distal occlusion of the middle cerebral artery did not induce a greater lesion size in the KO compared to the WT mice, neither did traumatic brain injury (TBI) (unpublished results). Interestingly, forelimb skill training induced neurogenesis in the uninjured WT mice, while it modestly induced neurogenesis in the $\mathrm{KO}$ mice after TBI (unpublished results). This suggests that brain injury and behavioral training elicit more growth promoting signals aside from VEGF that are conducive for neurogenesis in the Emx1 $\mathrm{KO}$ mice.

\section{REFERENCES}

Amrom, D., Tanyalcin, I., Verhelst, H., Deconinck, N., Brouhard, G. J., Decarie, J. C., et al. (2014). Polymicrogyria with dysmorphic basal ganglia? Think tubulin! Clin. Genet. 85, 178-183. doi: 10.1111/cge.12141

Bao, W. L., Lu, S. D., Wang, H., and Sun, F. Y. (1999). Intraventricular vascular endothelial growth factor antibody increases infarct volume following transient cerebral ischemia. Zhongguo Yao Li Xue Bao 20, 313-318.

Barkovich, A. J., Guerrini, R., Kuzniecky, R. I., Jackson, G. D., and Dobyns, W. B. (2012). A developmental and genetic classification for malformations of cortical development: update 2012. Brain 135(Pt 5), 1348-1369. doi: 10.1093/brain/aws019

Bellenchi, G. C., Gurniak, C. B., Perlas, E., Middei, S., Ammassari-Teule, M., and Witke, W. (2007). N-cofilin is associated with neuronal migration disorders and cell cycle control in the cerebral cortex. Genes Dev. 21, 2347-2357. doi: $10.1101 / \mathrm{gad} .434307$

Beutler, E. (2007). PGK deficiency. Br. J. Haematol. 136, 3-11. doi: 10.1111/j.13652141.2006.06351.x
In summary, we have identified Cofilin 1 as one of the proteins differentially regulated in NSCs between embryonic Emx1 WT and $\mathrm{KO}$ forebrains. The defect in Cofilin1 phosphorylation induced by VEGF or other growth factors may, in part, be responsible for the reduced neurogenesis observed during brain development and in adult CNS that underwent brain insult. Future studies are needed to identify pertinent neurogenesis signal pathways that still remain unaffected by Emx1 gene deletion. In addition, several identified differentially expressed proteins would be subject for further analysis to assess their exact role in neurogenesis and their contribution to the pathologic phenotype of Emx1 mutant.

\section{AUTHOR CONTRIBUTIONS}

FK performed the proteomic pathway analysis and contributed to the interpretation and writing. $\mathrm{KH}$ conducted the migration assay and validated the differential expression of cofilin and $\mathrm{p}$ cofilin. MN performed the 2D-PAGE and MS-MS analysis. SF contributed to cell counting. KJ contributed to western blot analysis. JL designed the experiments and wrote the manuscript.

\section{FUNDING}

This work was supported by NIH grant R01 NS071050 (JL), VA merit award I01RX000655 (JL), and National Natural Science Foundation of China No.81403479 (SF).

\section{ACKNOWLEDGMENTS}

We thank the UCSF Mass Spectrometry Core Facility for the service and assistance in identifying differentially expressed proteins. We are also grateful to Ms. Yang Fan for the technical assistance in NSC culture.

\section{SUPPLEMENTARY MATERIAL}

The Supplementary Material for this article can be found online at: http://journal.frontiersin.org/article/10.3389/fnmol. 2016.00098

Bishop, K. M., Garel, S., Nakagawa, Y., Rubenstein, J. L., and O’Leary, D. D. (2003). Emx1 and Emx2 cooperate to regulate cortical size, lamination, neuronal differentiation, development of cortical efferents, and thalamocortical pathfinding. J. Comp. Neurol. 457, 345-360. doi: 10.1002/cne.10550

Bishop, K. M., Rubenstein, J. L., and O'Leary, D. D. (2002). Distinct actions of Emx1, Emx2, and Pax6 in regulating the specification of areas in the developing neocortex. J. Neurosci. 22, 7627-7638.

Boncinelli, E., Gulisano, M., Spada, F., and Broccoli, V. (1995). Emx and Otx gene expression in the developing mouse brain. Ciba Found. Symp. 193, 100-116. discussion: 117-126.

Bonnet, A., Lagarrigue, S., Liaubet, L., Robert-Granié, C., Sancristobal, M., and Tosser-Klopp, G. (2009). Pathway results from the chicken data set using GOTM, Pathway Studio and Ingenuity softwares. BMC Proc. 3(Suppl. 4):S11. doi: 10.1186/1753-6561-3-s4-s11

Cao, B. J., and Li, Y. (2002). Reduced anxiety- and depression-like behaviors in Emx1 homozygous mutant mice. Brain Res. 937, 32-40. doi: 10.1016/S00068993(02)02461-7

Carlier, M. F., Laurent, V., Santolini, J., Melki, R., Didry, D., Xia, G. X., et al. (1997). Actin depolymerizing factor (ADF/cofilin) enhances the rate of filament 
turnover: implication in actin-based motility. J. Cell Biol. 136, 1307-1322. doi: 10.1083/jcb.136.6.1307

Cecchi, C., and Boncinelli, E. (2000). Emx homeogenes and mouse brain development. Trends Neurosci. 23, 347-352. doi: 10.1016/S01662236(00)01608-8

Chan, C. H., Godinho, L. N., Thomaidou, D., Tan, S. S., Gulisano, M., and Parnavelas, J. G. (2001). Emx1 is a marker for pyramidal neurons of the cerebral cortex. Cereb. Cortex 11, 1191-1198. doi: 10.1093/cercor/11.12.1191

Chou, S. J., Perez-Garcia, C. G., Kroll, T. T., and O'Leary, D. D. (2009). Lhx2 specifies regional fate in Emx1 lineage of telencephalic progenitors generating cerebral cortex. Nat. Neurosci. 12, 1381-1389. doi: 10.1038/nn.2427

Cocas, L. A., Miyoshi, G., Carney, R. S., Sousa, V. H., Hirata, T., Jones, K. R., et al. (2009). Emx1-lineage progenitors differentially contribute to neural diversity in the striatum and amygdala. J. Neurosci. 29, 15933-15946. doi: 10.1523/JNEUROSCI.2525-09.2009

Cushion, T. D., Dobyns, W. B., Mullins, J. G., Stoodley, N., Chung, S. K., Fry, A. E., et al. (2013). Overlapping cortical malformations and mutations in TUBB2B and TUBA1A. Brain 136(Pt 2), 536-548. doi: 10.1093/brain/aws338

Cushion, T. D., Paciorkowski, A. R., Pilz, D. T., Mullins, J. G., Seltzer, L. E., Marion, R. W., et al. (2014). De novo mutations in the beta-tubulin gene TUBB2A cause simplified gyral patterning and infantile-onset epilepsy. Am. J. Hum. Genet. 94, 634-641. doi: 10.1016/j.ajhg.2014.03.009

Daraselia, N., Wang, Y., Budoff, A., Lituev, A., Potapova, O., Vansant, G., et al. (2012). Molecular signature and pathway analysis of human primary squamous and adenocarcinoma lung cancers. Am. J. Cancer Res. 2, 93-103.

Dehmelt, L., and Halpain, S. (2004). Actin and microtubules in neurite initiation: are MAPs the missing link? J. Neurobiol. 58, 18-33. doi: 10.1002/neu.10284

Dehmelt, L., and Halpain, S. (2005). The MAP2/Tau family of microtubuleassociated proteins. Genome Biol. 6:204. doi: 10.1186/gb-2004-6-1-204

de Melo, J., Du, G., Fonseca, M., Gillespie, L. A., Turk, W. J., Rubenstein, J. L., et al. (2005). Dlx1 and Dlx2 function is necessary for terminal differentiation and survival of late-born retinal ganglion cells in the developing mouse retina. Development 132, 311-322. doi: 10.1242/dev.01560

Desai, A., and Mitchison, T. J. (1997). Microtubule polymerization dynamics. Annu. Rev. Cell Dev. Biol. 13, 83-117. doi: 10.1146/annurev.cellbio.13.1.83

Fathi, A., Hatami, M., Vakilian, H., Han, C. L., Chen, Y. J., Baharvand, H., et al. (2014). Quantitative proteomics analysis highlights the role of redox hemostasis and energy metabolism in human embryonic stem cell differentiation to neural cells. J. Proteomics 101, 1-16. doi: 10.1016/j.jprot.2014.02.002

Ferhat, L., Charton, G., Represa, A., Ben-Ari, Y., der Terrossian, E., and Khrestchatisky, M. (1996). Acidic calponin cloned from neural cells is differentially expressed during rat brain development. Eur. J. Neurosci. 8, 1501-1509. doi: 10.1111/j.1460-9568.1996.tb01612.x

Ferhat, L., Esclapez, M., Represa, A., Fattoum, A., Shirao, T., and BenAri, Y. (2003). Increased levels of acidic calponin during dendritic spine plasticity after pilocarpine-induced seizures. Hippocampus 13, 845-858. doi: 10.1002/hipo.10136

Frisén, J. (2016). Neurogenesis and gliogenesis in nervous system plasticity and repair. Annu. Rev. Cell Dev. Biol. 32, 127-141. doi: 10.1146/annurev-cellbio111315-124953

Gavalas, A., Ruhrberg, C., Livet, J., Henderson, C. E., and Krumlauf, R. (2003). Neuronal defects in the hindbrain of Hoxa1, Hoxb1 and Hoxb2 mutants reflect regulatory interactions among these Hox genes. Development 130, 5663-5679. doi: $10.1242 /$ dev.00802

Gulisano, M., Broccoli, V., Pardini, C., and Boncinelli, E. (1996). Emx1 and Emx2 show different patterns of expression during proliferation and differentiation of the developing cerebral cortex in the mouse. Eur. J. Neurosci. 8, 1037-1050. doi: 10.1111/j.1460-9568.1996.tb01590.x

Guo, H., Christoff, J. M., Campos, V. E., Jin, X. L., and Li, Y. (2000). Normal corpus callosum in Emx1 mutant mice with C57BL/6 background. Biochem. Biophys. Res. Commun. 276, 649-653. doi: 10.1006/bbrc.2000.3533

Guzik, B. W., and Goldstein, L. S. (2004). Microtubule-dependent transport in neurons: steps towards an understanding of regulation, function and dysfunction. Curr. Opin. Cell Biol. 16, 443-450. doi: 10.1016/j.ceb.2004.06.002

Han, Y., Yin, H., Xu, Y., Zhu, Q., Luo, J., Wang, X., et al. (2012). Increased expression of calponin-3 in epileptic patients and experimental rats. Exp. Neurol. 233, 430-437. doi: 10.1016/j.expneurol.2011.11.014

Hatanaka, H., Ogura, K., Moriyama, K., Ichikawa, S., Yahara, I., and Inagaki, F. (1996). Tertiary structure of destrin and structural similarity between two actin-regulating protein families. Cell 85, 1047-1055. doi: 10.1016/S0092 8674(00)81305-7

Hawkins, M., Pope, B., MacIver, S. K., and Weeds, A. G. (1993). Human actin depolymerizing factor mediates a $\mathrm{pH}$-sensitive destruction of actin filaments. Biochemistry 32, 9985-9993. doi: 10.1021/bi00089a014

Hoffrogge, R., Beyer, S., Hübner, R., Mikkat, S., Mix, E., Scharf, C., et al. (2007). 2-DE profiling of GDNF overexpression-related proteome changes in differentiating ST14A rat progenitor cells. Proteomics 7, 33-46. doi: $10.1002 /$ pmic. 200600614

Hong, S. M., Liu, Z., Fan, Y., Neumann, M., Won, S. J., Lac, D., et al. (2007). Reduced hippocampal neurogenesis and skill reaching performance in adult Emx1 mutant mice. Exp. Neurol. 206, 24-32. doi: 10.1016/j.expneurol. 2007.03.028

Hsiao, K. C., Shih, N. Y., Fang, H. L., Huang, T. S., Kuo, C. C., Chu, P. Y., et al. (2013). Surface alpha-enolase promotes extracellular matrix degradation and tumor metastasis and represents a new therapeutic target. PLoS ONE 8:e69354. doi: 10.1371/journal.pone.0069354

Ip, J. P., Fu, A. K., and Ip, N. Y. (2014). CRMP2: functional roles in neural development and therapeutic potential in neurological diseases. Neuroscientist 20, 589-598. doi: 10.1177/1073858413514278

Jaworski, J., Kapitein, L. C., Gouveia, S. M., Dortland, B. R., Wulf, P. S., Grigoriev, I., et al. (2009). Dynamic microtubules regulate dendritic spine morphology and synaptic plasticity. Neuron 61, 85-100. doi: 10.1016/j.neuron.2008.11.013

Jin, K., Mao, X. O., and Greenberg, D. A. (2006). Vascular endothelial growth factor stimulates neurite outgrowth from cerebral cortical neurons via Rho kinase signaling. J. Neurobiol. 66, 236-242. doi: 10.1002/neu.20215

Kuiper, J. W., van Horssen, R., Oerlemans, F., Peters, W., van Dommelen, M. M., te Lindert, M. M., et al. (2009). Local ATP generation by braintype creatine kinase (CK-B) facilitates cell motility. PLoS ONE 4:e5030. doi: 10.1371/journal.pone.0005030

Kumar, R. A., Pilz, D. T., Babatz, T. D., Cushion, T. D., Harvey, K., Topf, M., et al. (2010). TUBA1A mutations cause wide spectrum lissencephaly (smooth brain) and suggest that multiple neuronal migration pathways converge on alpha tubulins. Hum. Mol. Genet. 19, 2817-2827. doi: 10.1093/hmg/ddq182

Lamszus, K., Schmidt, N. O., Jin, L., Laterra, J., Zagzag, D., Way, D., et al. (1998). Scatter factor promotes motility of human glioma and neuromicrovascular endothelial cells. Int. J. Cancer 75, 19-28.

Li, H., Bishop, K. M., and O’Leary, D. D. (2006). Potential target genes of EMX2 include Odz/Ten-M and other gene families with implications for cortical patterning. Mol. Cell. Neurosci. 33, 136-149. doi: 10.1016/j.mcn.2006.06.012

Li, Q., Ford, M. C., Lavik, E. B., and Madri, J. A. (2006). Modeling the neurovascular niche: VEGF- and BDNF-mediated cross-talk between neural stem cells and endothelial cells: an in vitro study. J. Neurosci. Res. 84, 1656-1668. doi: 10.1002/jnr.21087

Lillien, L. (2014). Rostral-caudal distribution of Emxl-lineage stem/transit amplifying cells and lineage progression in embryonic cortex depend on Hedgehog signaling. Dev. Neurobiol. 74, 1096-1109. doi: 10.1002/dneu.22186

Lim, J. W., Donahoo, A. L., Bunt, J., Edwards, T. J., Fenlon, L. R., Liu, Y., et al. (2015). EMX1 regulates NRP1-mediated wiring of the mouse anterior cingulate cortex. Development 142, 3746-3757. doi: 10.1242/dev.119909

Liu, H., and Song, N. (2016). Molecular mechanism of adult neurogenesis and its association with human brain diseases. J. Cent. Nerv. Syst. Dis. 8, 5-11. doi: 10.4137/JCNSD.S32204

Louis, S. A., and Reynolds, B. A. (2010). Neurosphere and neural colony-forming cell assays. Protoc. Neural Cell Cult. 10, 1-28. doi: 10.1007/978-1-60761292-6_1

Madri, J. A. (2009). Modeling the neurovascular niche: implications for recovery from CNS injury. J. Physiol. Pharmacol. 60(Suppl. 4), 95-104.

Maurer, M. H., Tripps, W. K., Feldmann, R. E. Jr., and Kuschinsky, W. (2003). Expression of vascular endothelial growth factor and its receptors in rat neural stem cells. Neurosci. Lett. 344, 165-168. doi: 10.1016/S0304-3940(03)00407-5

Meberg, P. J. (2000). Signal-regulated ADF/cofilin activity and growth cone motility. Mol. Neurobiol. 21, 97-107. doi: 10.1385/MN:21:1-2:097

Meberg, P. J., and Bamburg, J. R. (2000). Increase in neurite outgrowth mediated by overexpression of actin depolymerizing factor. J. Neurosci. 20, 2459-2469.

Mi, H., Dong, Q., Muruganujan, A., Gaudet, P., Lewis, S., and Thomas, P. D. (2010). PANTHER version 7: improved phylogenetic trees, orthologs and collaboration with the Gene Ontology Consortium. Nucleic Acids Res. 38, D204-D210. doi: 10.1093/nar/gkp1019 
Mi, H., Poudel, S., Muruganujan, A., Casagrande, J. T., and Thomas, P. D. (2016). PANTHER version 10: expanded protein families and functions, and analysis tools. Nucleic Acids Res. 44, D336-D342. doi: 10.1093/nar/gkv1194

Muzio, L., and Mallamaci, A. (2003). Emx1, emx2 and pax6 in specification, regionalization and arealization of the cerebral cortex. Cereb. Cortex 13, 641-647. doi: 10.1093/cercor/13.6.641

Novitch, B. G., and Butler, S. J. (2009). Reducing the mystery of neuronal differentiation. Cell 138, 1062-1064. doi: 10.1016/j.cell.2009.09.001

Ochi, H., Horiuchi, I., Araki, N., Toda, T., Araki, T., Sato, K., et al. (2002). Proteomic analysis of human brain identifies alpha-enolase as a novel autoantigen in Hashimoto's encephalopathy. FEBS Lett. 528, 197-202. doi: 10.1016/S0014-5793(02)03307-0

Ohab, J. J., and Carmichael, S. T. (2008). Poststroke neurogenesis: emerging principles of migration and localization of immature neurons. Neuroscientist 14, 369-380. doi: 10.1177/1073858407309545

Panganiban, G., and Rubenstein, J. L. (2002). Developmental functions of the Distal-less/Dlx homeobox genes. Development 129, 4371-4386.

Patarnello, T., Bargelloni, L., Boncinelli, E., Spada, F., Pannese, M., and Broccoli, V. (1997). Evolution of Emx genes and brain development in vertebrates. Proc. Biol. Sci. 264, 1763-1766. doi: 10.1098/rspb.1997.0244

Pellegrini, M., Mansouri, A., Simeone, A., Boncinelli, E., and Gruss, P. (1996). Dentate gyrus formation requires Emx2. Development 122, 3893-3898.

Piper, M., Dawson, A. L., Lindwall, C., Barry, G., Plachez, C., and Richards, L. J. (2007). Emx and Nfi genes regulate cortical development and axon guidance in the telencephalon. Novartis Found. Symp. 288, 230-242. discussion: 242-235, 276-281.

Pyatnitskiy, M., Mazo, I., Shkrob, M., Schwartz, E., and Kotelnikova, E. (2014). Clustering gene expression regulators: new approach to disease subtyping. PLoS ONE 9:e84955. doi: 10.1371/journal.pone.0084955

Qiu, M., Anderson, S., Chen, S., Meneses, J. J., Hevner, R., Kuwana, E., et al. (1996). Mutation of the Emx-1 homeobox gene disrupts the corpus callosum. Dev. Biol. 178, 174-178. doi: 10.1006/dbio.1996.0207

Rami, G., Caillard, O., Medina, I., Pellegrino, C., Fattoum, A., Ben-Ari, Y., et al. (2006). Change in the shape and density of dendritic spines caused by overexpression of acidic calponin in cultured hippocampal neurons. Hippocampus 16, 183-197. doi: 10.1002/hipo.20145

Rech, T. H., Vieira, S. R., Nagel, F., Brauner, J. S., and Scalco, R. (2006). Serum neuron-specific enolase as early predictor of outcome after in-hospital cardiac arrest: a cohort study. Crit. Care 10, R133. doi: 10.1186/cc5046

Represa, A., Trabelsi-Terzidis, H., Plantier, M., Fattoum, A., Jorquera, I., Agassandian, C., et al. (1995). Distribution of caldesmon and of the acidic isoform of calponin in cultured cerebellar neurons and in different regions of the rat brain: an immunofluorescence and confocal microscopy study. Exp. Cell Res. 221, 333-343. doi: 10.1006/excr.1995.1383

Schänzer, A., Wachs, F. P., Wilhelm, D., Acker, T., Cooper-Kuhn, C., Beck, H., et al. (2004). Direct stimulation of adult neural stem cells in vitro and neurogenesis in vivo by vascular endothelial growth factor. Brain Pathol. 14, 237-248. doi: 10.1111/j.1750-3639.2004.tb00060.x

Schmidt, N. O., Koeder, D., Messing, M., Mueller, F. J., Aboody, K. S., Kim, S. U., et al. (2009). Vascular endothelial growth factor-stimulated cerebral microvascular endothelial cells mediate the recruitment of neural stem cells to the neurovascular niche. Brain Res. 1268, 24-37. doi: 10.1016/j.brainres.2009.02.065

Sen, S., Reichert, H., and VijayRaghavan, K. (2013). Conserved roles of ems/Emx and otd/Otx genes in olfactory and visual system development in Drosophila and mouse. Open Biol. 3:120177. doi: 10.1098/rsob.120177

Shinozaki, K., Yoshida, M., Nakamura, M., Aizawa, S., and Suda, Y. (2004). Emx1 and Emx2 cooperate in initial phase of archipallium development. Mech. Dev. 121, 475-489. doi: 10.1016/j.mod.2004.03.013

Simeone, A., Acampora, D., Mallamaci, A., Stornaiuolo, A., D'Apice, M. R., Nigro, V., et al. (1993). A vertebrate gene related to orthodenticle contains a homeodomain of the bicoid class and demarcates anterior neuroectoderm in the gastrulating mouse embryo. EMBO J. 12, 2735-2747.

Simeone, A., Gulisano, M., Acampora, D., Stornaiuolo, A., Rambaldi, M., and Boncinelli, E. (1992). Two vertebrate homeobox genes related to the Drosophila empty spiracles gene are expressed in the embryonic cerebral cortex. EMBO J. $11,2541-2550$.

Stocker, A. M., and O'Leary, D. D. (2016). Emx1 is required for neocortical area patterning. PLoS ONE 11:e0149900. doi: 10.1371/journal.pone.0149900
Sun, Y., Jin, K., Childs, J. T., Xie, L., Mao, X. O., and Greenberg, D. A. (2006). Vascular endothelial growth factor-B (VEGFB) stimulates neurogenesis: evidence from knockout mice and growth factor administration. Dev. Biol. 289, 329-335. doi: 10.1016/j.ydbio.2005.10.016

Tamamaki, N. (2005). Origin of the neocortical subependymal cells speculated by Emx1 and GAD67 expression. Chem. Senses 30(Suppl. 1), i111-i112. doi: 10.1093/chemse/bjh139

Tan, M., Cha, C., Ye, Y., Zhang, J., Li, S., Wu, F., et al. (2015). CRMP4 and CRMP2 interact to coordinate cytoskeleton dynamics, regulating growth cone development and axon elongation. Neural Plast. 2015:947423. doi: $10.1155 / 2015 / 947423$

Thored, P., Wood, J., Arvidsson, A., Cammenga, J., Kokaia, Z., and Lindvall, O. (2007). Long-term neuroblast migration along blood vessels in an area with transient angiogenesis and increased vascularization after stroke. Stroke 38, 3032-3039. doi: 10.1161/STROKEAHA.107.488445

Togi, S., Muromoto, R., Hirashima, K., Kitai, Y., Okayama, T., Ikeda, O., et al. (2016). A new STAT3-binding partner, ARL3, enhances the phosphorylation and nuclear accumulation of STAT3. J. Biol. Chem. 291, 11161-11171. doi: 10.1074/jbc.M116.724849

Ulmer, B., Hagenlocher, C., Schmalholz, S., Kurz, S., Schweickert, A., Kohl, A., et al. (2013). Calponin 2 acts as an effector of noncanonical Wnt-mediated cell polarization during neural crest cell migration. Cell Rep. 3, 615-621. doi: 10.1016/j.celrep.2013.02.015

Vermillion, K. L., Lidberg, K. A., and Gammill, L. S. (2014). Expression of actinbinding proteins and requirement for actin-depolymerizing factor in chick neural crest cells. Dev. Dyn. 243, 730-738. doi: 10.1002/dvdy.24105

von Frowein, J., Wizenmann, A., and Götz, M. (2006). The transcription factors Emx1 and Emx2 suppress choroid plexus development and promote neuroepithelial cell fate. Dev. Biol. 296, 239-252. doi: 10.1016/j.ydbio.2006.04.461

Ward, M. C., and Cunningham, A. M. (2015). Developmental expression of vascular endothelial growth factor receptor 3 and vascular endothelial growth factor $\mathrm{C}$ in forebrain. Neuroscience 303, 544-557. doi: 10.1016/j.neuroscience.2015.04.063

Yang, X., and Cepko, C. L. (1996). Flk-1, a receptor for vascular endothelial growth factor (VEGF), is expressed by retinal progenitor cells. J. Neurosci. 16, 6089-6099.

Yoshimura, T., Kawano, Y., Arimura, N., Kawabata, S., Kikuchi, A., and Kaibuchi, K. (2005). GSK-3beta regulates phosphorylation of CRMP-2 and neuronal polarity. Cell 120, 137-149. doi: 10.1016/j.cell.2004.11.012

Yu, Z., Willmarth, N. E., Zhou, J., Katiyar, S., Wang, M., Liu, Y., et al. (2010). microRNA 17/20 inhibits cellular invasion and tumor metastasis in breast cancer by heterotypic signaling. Proc. Natl. Acad. Sci. U.S.A. 107, 8231-8236. doi: 10.1073/pnas.1002080107

Yuryev, A., Kotelnikova, E., and Daraselia, N. (2009). Ariadne's chemeffect and pathway studio knowledge base. Expert Opin. Drug Discov. 4, 1307-1318. doi: $10.1517 / 17460440903413488$

Zhang, L., Luo, J., Wan, P., Wu, J., Laski, F., and Chen, J. (2011). Regulation of cofilin phosphorylation and asymmetry in collective cell migration during morphogenesis. Development 138, 455-464. doi: 10.1242/dev.046870

Zhang, S., Xie, R., Zhao, T., Yang, X., Han, L., Ye, F., et al. (2014). Neural stem cells preferentially migrate to glioma stem cells and reduce their stemness phenotypes. Int. J. Oncol. 45, 1989-1996. doi: 10.3892/ijo.2014.2629

Zhou, Y., Jiang, H., Gu, J., Tang, Y., Shen, N., and Jin, Y. (2013). MicroRNA-195 targets ADP-ribosylation factor-like protein 2 to induce apoptosis in human embryonic stem cell-derived neural progenitor cells. Cell Death Dis. 4:e695. doi: $10.1038 /$ cddis. 2013.195

Conflict of Interest Statement: The authors declare that the research was conducted in the absence of any commercial or financial relationships that could be construed as a potential conflict of interest.

Copyright (c) 2016 Kobeissy, Hansen, Neumann, Fu, Jin and Liu. This is an openaccess article distributed under the terms of the Creative Commons Attribution License (CC BY). The use, distribution or reproduction in other forums is permitted, provided the original author(s) or licensor are credited and that the original publication in this journal is cited, in accordance with accepted academic practice. No use, distribution or reproduction is permitted which does not comply with these terms. 